\title{
MYCOLIC ACIDS: STRUCTURE, BIOSYNTHESIS AND PHYSIOLOGICAL FUNCTIONS
}

\author{
Clifton E. Barry III*, Richard E. Lee, Khisimusi Mdluli, \\ Andrea E. Sampson, Benjamin G. Schroeder, Richard A. Slayden \\ and Ying Yuan \\ Tuberculosis Research Section, Rocky Mountain Laboratories, NIAID, NIH, Hamilton, \\ MT 59840, USA
}

\section{CONTENTS}

I. Structure and identification of mycolic acids

A. Generalized structures and properties of mycolic acids $\quad 143$

1. An historical perspective on mycolic acid structure

2. General motifs found in mycolic acids 144

3. Preparation and identification of mycolic acids $\quad 145$

B. Structural variation in nonmycobacterial mycolic acids 146

C. Structural variation in mycobacterial mycolic acids $\quad 148$

1. Chemotaxonomy of mycobacterial species 148

2. Class variation between species 149

3. Microheterogeneity 149

152

A. Mero and alpha branch synthesis 152

1. Short-chain lipid synthesis: the alpha branch and mero primers 152

2. Long-chain lipid synthesis: the mero-INH connection 154

B. Meromycolate modification reactions 156

1. The desaturation $\quad 156$

2. Modifications involving methyl transfer from SAM 157

3. Oxidative modifications of the meromycolate 160

C. The condensation and carriers $\quad 161$

D. Cell-free "complete mycolate" synthesizing systems 163

III. Physiological function of mycolic acids $\quad 164$

A. General features and functions of the cell wall of mycolic acid containing bacteria 164

B. Structure of the mycobacterial cell wall 165

$\begin{array}{ll}\text { 1. Electron microscopic examinations } & 165\end{array}$

2. Model of the mycobacterial cell wall 167

3. Biophysical examinations of cell wall structure 167

C. Physiological roles of structural variation in cell-wall bound mycolic acids $\quad 168$

168

2. Cis/trans olefins and thermal adaptation 169

3. Trans cyclopropanation $\quad 170$

4. Cis cyclopropanation 170

$\begin{array}{ll}\text { 5. Oxygenated mycolates } & 171\end{array}$

D. Physiological roles of non-cell wall bound mycolic acids $\quad 172$

1. The role of mycolic acid in the immune response to mycobacterial infection 172

2. The role of mycolic acids in the pathogenesis of mycobacterial disease 172

3. Adjuvant activity and immunogenicity 173

\section{STRUCTURE AND IDENTIFICATION OF MYCOLIC ACIDS}

\section{A. Generalized Structures and Properties of Mycolic Acids}

\section{An Historical Perspective on Mycolic Acid Structure}

R. J. Anderson at the Chemistry Department of Yale University first proposed, in 1938, to call the ether-soluble, unsaponifiable, high-molecular weight hydroxy acid of the

*Correspondence to Clifton E. Barry III, 903 S. Fourth St., Hamilton, MT 59840-2999, USA. Tel.: 406.363.9309; fax: 406.363.9321; e-mail: clifton_barry@nih.gov. 
human tubercle bacillus "mycolic acid". ${ }^{1-3}$ Initially the available structural information was very sparse; pyrolytic cleavage yielded hexacosanoic acid and an unidentified longchain component which together showed a rough empirical formula of $\mathrm{C}_{88} \mathrm{H}_{172} \mathrm{O}_{4}$ or $\mathrm{C}_{88} \mathrm{H}_{176} \mathrm{O}_{4}$. In many ways the history of the structure elucidation of mycolic acids parallels the history of the development of the modern tools of analytical chemistry. As our ability to probe more precisely the exact nature of such molecules has advanced, the true complexity of the substance originally defined as mycolic acid has become more apparent. What was once described as a single component which was liberated upon saponification of the "wax" isolated from Mycobacterium tuberculosis, we now recognize as a broad family of over 500 intimately related chemical structures. This staggering number of individual mycolic acid components, which are quantitatively the major component of the cell wall, in a single bacterium is a reflection of the biological role and importance of these molecules. With the recent completion of the entire genomic sequence of $M$. tuberculosis and the development of tools for the genetic manipulation of slow-growing mycobacteria, the biosynthetic pathways and the molecular basis for this diversity are beginning to become clear. These tools have allowed an unprecedented exploration of the functional roles played by many of these unique structures and for the first time the molecular mechanisms and the selective pressures which led to their evolution can be fully appreciated. Not since Minnikin's extensive review in 1982 has the field been comprehensively summarized. ${ }^{4}$ The rapid pace of the research directly related to mycolic acids makes this a difficult area to review, but the vital importance of understanding the biosynthesis of mycolic acids and how inhibitors of this pathway may lead to new therapeutics makes this a critical time to evaluate where we are and where we are headed.

\section{General Motifs Found in Mycolic Acids}

Besides the basic $\beta$-hydroxy- $\alpha$-alkyl branched structure which was elucidated following the initial characterization, 5,6 mycolic acids contain diverse functionalities and can broadly be separated into classes according to these groups (see Fig. 1 for examples of the types of mycolates commonly encountered among mycobacteria). In the pyrolytic cleavage of mycolic acids the intact fatty acid released is often referred to as the $\alpha$ branch since it occupies the alpha position with respect to the carboxylic acid group (Fig. 1A). The aldehyde released is referred to as the meroaldehyde and the corresponding segment of the intact mycolate is often referred to as the meromycolate branch. Confusingly, mycolates possessing only desaturation and/or cyclopropanation in the meromycolate chain are known as $\alpha$-mycolic acids (Fig. 1B shows some representative examples of $\alpha$ mycolates), $\alpha$ in this case simply referring to their position on TLC. To distinguish between these two uses of " $\alpha$ ", when referring to the shorter acid released on pyrolysis we will use the term " $\alpha$ branch".

The unsaturations and cyclopropanes occurring within $\alpha$ mycolates may be either cis or trans, but when trans they also possess an adjacent methyl branch. Mycolates containing an $\alpha$-methyl-branched methyl ether in conjunction with desaturation or cyclopropanation (both cis and trans isomers of each) are termed methoxymycolates (Fig. 1C). Oxygenation of the meromycolate is also found in ketomycolates and epoxymycolates, which contain an $\alpha$-methyl-branched ketone or an $\alpha$-methyl-branched epoxide in conjunction with cis or trans desaturation or cyclopropanation and methyl branching. Mycolates known as wax esters contain desaturation or a cyclopropane and an internal ester group. In wax ester mycolates the major secondary alcohol formed by saponification is often characteristic of a species. ${ }^{7,8}$

All mycolic acids possess at least two chiral centers at the positions $\alpha$ and $\beta$ to the carboxylic acid. Among various mycobacterial species and various mycolic acids the stereochemistry at these two centers has been consistently found to be $R, R$, thus these two centers are erythro to each other. ${ }^{9-15}$ Outside of the mycobacteria the stereochemical information is much more limited, although the mycolates of Rhodococcus lentifragmentus 
A

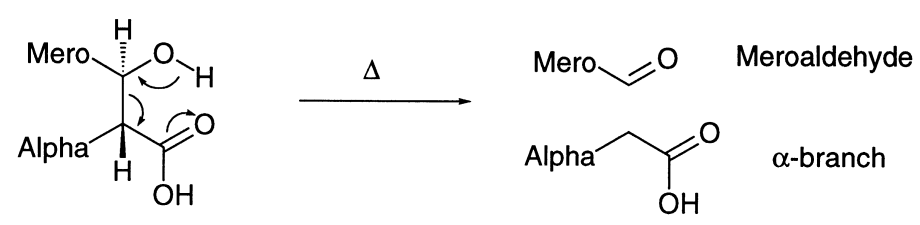

B

$\alpha$

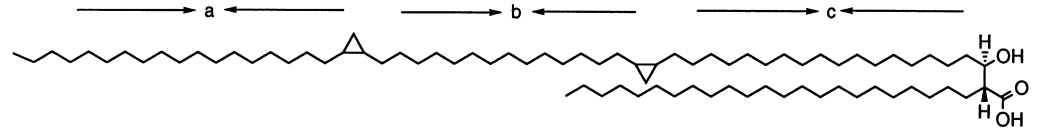

$\alpha_{1}$

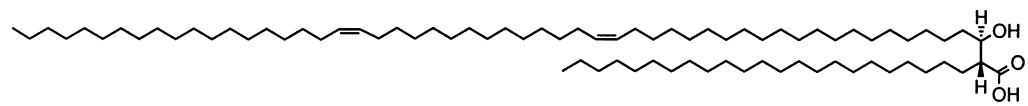

$\alpha_{2}$

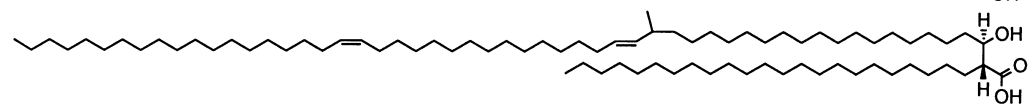

$\alpha^{\prime}$

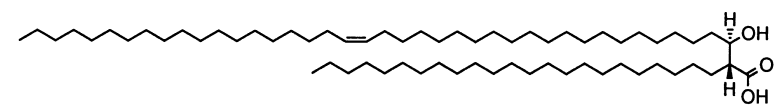

C

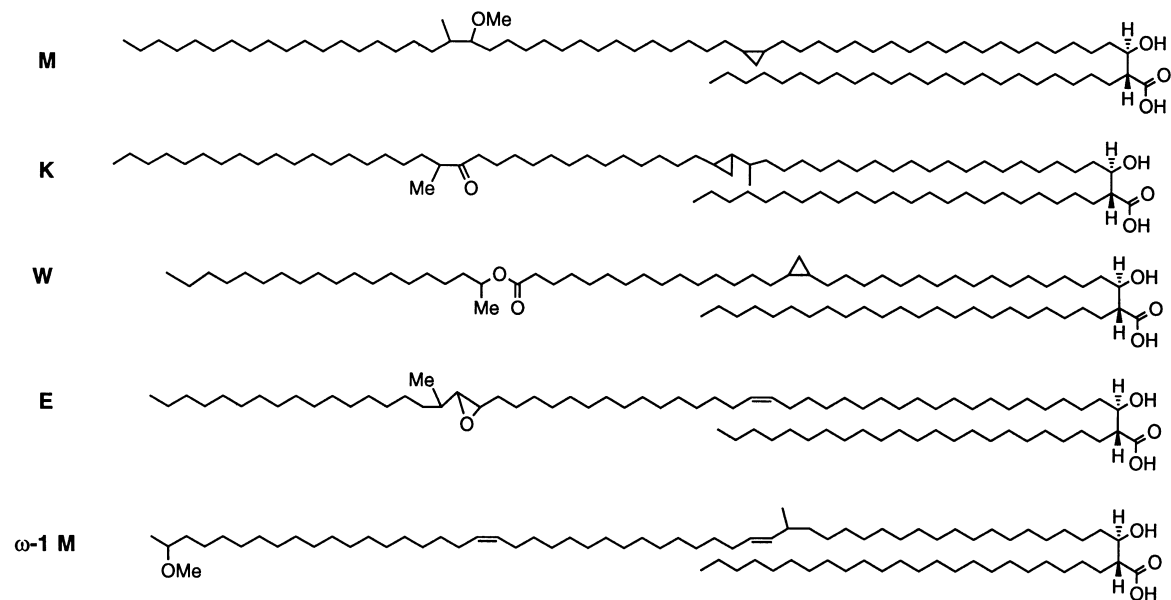

Fig. 1. (A) Fragmentation of mycolic acids via the thermally-induced cleavage of the $\beta$-hydroxy carboxylic acid to form the $\alpha$-branch and meroaldehyde. (B) Representative structures of a selection of $\alpha$ mycolic acids. (C) Representative stuctures of a variety of oxygenated mycolic acids. $\mathrm{M}$-methoxy, $\mathrm{K}$ - keto, $\mathrm{W}$ - wax ester, $\mathrm{E}$ - epoxy, $\omega-1 \mathrm{M}-\omega-1$ methoxy.

have been analyzed and found to conform to the $R, R$ stereochemistry by optical rotation. ${ }^{16}$

\section{Preparation and Identification of Mycolic Acids}

Mycolic acids exist in the cell in two basic forms: covalently bound to the cell wall, and loosely-associated with this insoluble matrix esterified to a variety of carbohydratecontaining molecules. Treatment of intact cells with mixtures of chloroform and methanol is suitable for extracting the smaller quantity of non-covalently attached mycolate. Such delipidated cells may then be treated under alkaline conditions to extract the mycolates of the cell wall (for a detailed procedure see Ref. ${ }^{17}$ ). These mycolates are typically 
separated as to class (less polar $\alpha$ mycolates from more polar oxygenated mycolates, for example) by silica gel chromatography of their methyl esters. Two-dimensional thinlayer chromatography (2-D TLC) has been used extensively to characterize mycolic acids in the field of mycolic acid chemotaxonomy. ${ }^{18,19}$ The first analysis by TLC and subsequent purification of individual mycolate classes allowed for their structural characterization using a variety of techniques such as IR, proton and carbon NMR, electronimpact MS, pyrolytic GC, as well as basic chemical analysis. An example of a 2-D TLC separation of the major classes of mycolic acids from Mycobacterium tuberculosis is shown in Fig. 2A. The three separable spots represent in order of increasing polarity $\alpha$ mycolates $(\alpha)$, methoxymycolates (M), and ketomycolates (K). 2-D TLC systems which incorporate silver ions into one dimension for a separation based on the presence and configuration of olefins have also been developed and may prove useful for separations which are not possible based on differential polarity (see for example Ref. ${ }^{20}$ ).

The $500 \mathrm{MHz}{ }^{1} \mathrm{H}-\mathrm{NMR}$ spectrum of the major $\alpha$ mycolate from $M$. tuberculosis is shown in Fig. 2D. This proton NMR spectrum contains many resonances characteristic of the generic mycolic acid structure in addition to the large aliphatic peaks at $21.0-1.5$ $\mathrm{ppm}$ and the terminal methyl resonances at 20.86 . Characteristic peaks are those attributable to the proton $\alpha$ to the carboxylic acid at 22.41 , the proton $\beta$ to the acid at 23.63 , the methylene protons $\gamma$ to the acid and $\beta$ to the hydroxyl group at 21.56 , and the first methylene of the $\alpha$ branch at 21.70 ; these resonances define the minimal mycolic acid spectrum. The cis cyclopropane peaks at $2-0.33,0.56$, and 0.66 are a characteristic of the $\alpha$ mycolates of $M$. tuberculosis.

More recent advances in analytical techniques using a combination of GC/MS, LC/ MS (electrospray), FAB-MS, and tandem MS-MS techniques have allowed mycolate structures to be studied in finer detail. ${ }^{7,21,22}$ Fig. 2B,C shows a typical HPLC trace and FAB mass spectrum of the $\alpha$ mycolate of $M$. tuberculosis. Although we will discuss in detail the extended series of isomeric peaks revealed by analysis of mycobacterial mycolates using current techniques, it is worth noting here that such extended ethylenic series, differing in molecular weight by exactly $28 \mathrm{amu}$, are entirely typical of mycolic acids from all of the organisms which produce such molecules.

\section{B. Structural Variation in Nonmycobacterial Mycolic Acids}

Mycolic acid-containing, chemotype IV cell wall actinomycetes form a distinct phylogenetic line named the mycolata. ${ }^{23,24}$ Mycolic acids have become one of the defining taxonomic characteristics of many species in genera such as Mycobacterium, Corynebacterium, Dietzia, Nocardia, Rhodococcus, and Tsukamurella. The difference in size among mycolates of various actinomycetes has been utilized widely as a taxonomic tool in their differentiation. ${ }^{25}$ This difference is easily assayed by reversed-phase HPLC $^{26,27}$ or simple solubility tests. ${ }^{28}$ While identification of genus solely by mycolate profiles must still be used with caution, there are clear distinctions in size between genera with only a few exceptions (Table 1). Unlike mycobacterial mycolates, desaturation is the only form of functionalization found in the other members of the mycolata family.

Corynebacteria produce corynomycolic acids which typically range in size from 30-36 carbons with an $\alpha$ branch of typically 16-18 carbons. The size, structure, and distribution of corynomycolates has been reviewed extensively. ${ }^{24,29}$ Short-chain analogs of fatty acids supplied exogenously are readily incorporated into corynomycolate ${ }^{30}$ Similarly to the Corynebacteria, the lesser known Dietzia genus produce 30-36 carbon mycolates. ${ }^{31,32}$

The genus Nocardia produce nocardomycolates with total chain lengths of approximately 50 carbons with $0-3$ double bonds and predominantly 16 to 18 carbon $\alpha$ branches. $N$. asteroides and $N$. brasilienus are human pathogens commonly isolated in clinical laboratories and thus have been well studied. ${ }^{33,34} N$. asteroides (strain IFO-3384) mycolates average 52 carbons with up to four double bonds as shown by GC-MS. ${ }^{35}$ The mycolic acid profile was found to differ significantly with respect to desaturation when 

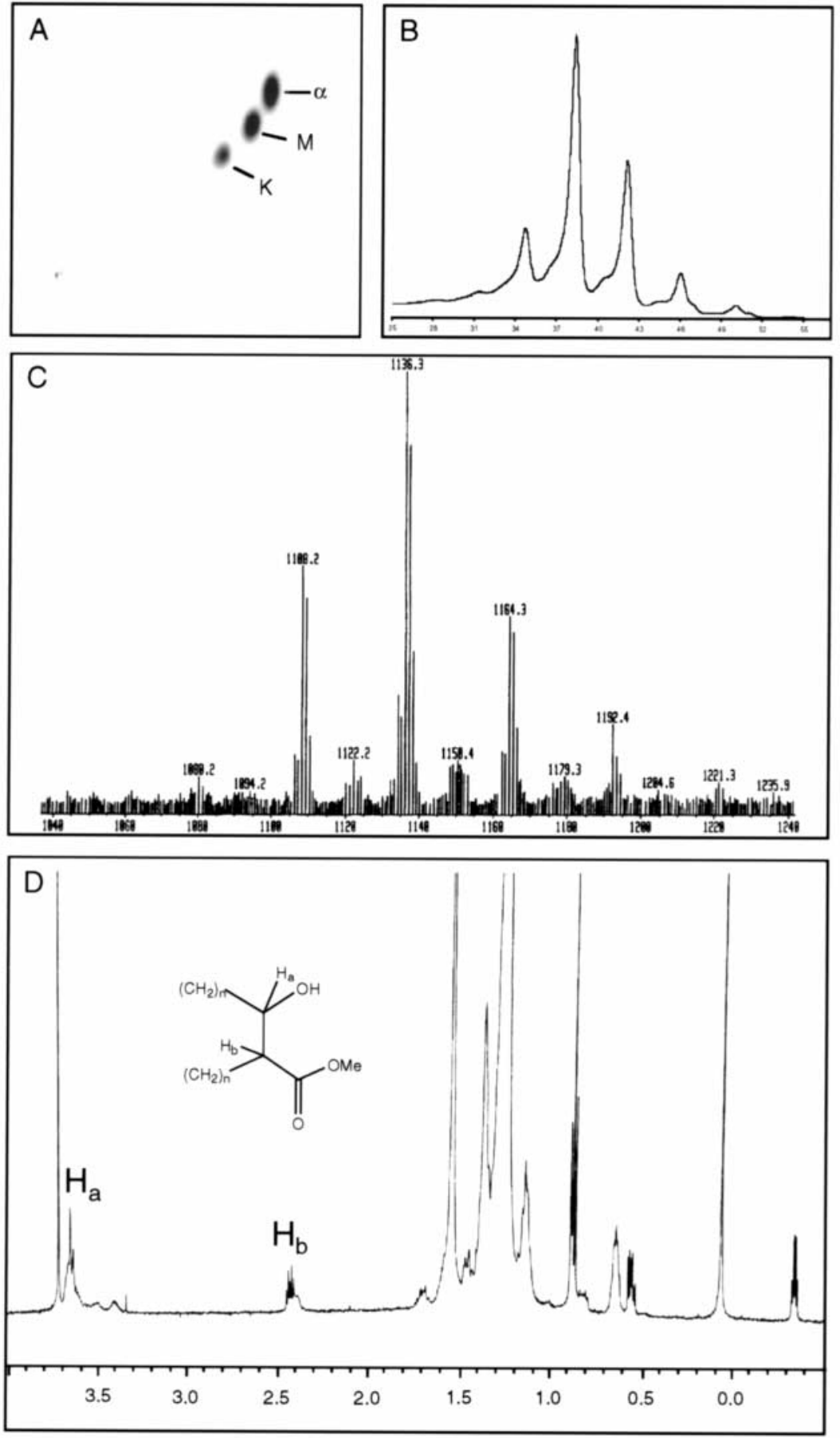

Fig. 2. Basic physical characteristics of mycolic acids from M. tuberculosis H37Rv. (A) 2D-TLC of the major mycolic acids. The vertical dimension (bottom to top) is separation based on polarity (silica gel) while the horizontal dimension (left to right) is separation based on argentation TLC. $^{20}$ (B) HPLC profile of the purified $\alpha$ mycolates separated by reversed-phase HPLC using a gradient of dioxane in acetonitrile and detection using an evaporative light-scattering device. (C) FAB mass spectrum of the $\alpha$ mycolates shown in B (free acid). The major peaks correspond to isomers with a total carbon number of 76(1108.2), 78(1136.3), 80(1164.3), and 82 (1192.4). (D) $500 \mathrm{MHz}{ }^{1} \mathrm{H}-\mathrm{NMR}$ spectrum of mycolates from B described in text and collected in deuterochloroform. 
Table 1. Variation in size of mycolic acid with genus of mycolata

\begin{tabular}{lccc}
\hline Genus & Total no. of carbons & Number of double bonds & $\begin{array}{c}\alpha \text {-Branch released by } \\
\text { Pyrolysis }\end{array}$ \\
\hline Corynebacteria & $22-36$ & $0-2$ & $14-18$ \\
Gordona & $48-66$ & $1-4$ & $16-18$ \\
Mycobacteria & $60-90$ & 2 & $20-26$ \\
Nocardia & $44-60$ & $0-3$ & $12-18$ \\
Rodococcus & $34-48$ & $0-4$ & $12-18$ \\
Tsukamurella & $64-78$ & $1-6$ & $20-22$ \\
\hline
\end{tabular}

grown at different temperatures. When cultured at $50^{\circ} \mathrm{C}$ the nocardomycolates were fully saturated, but when cultured at $17^{\circ} \mathrm{C}$ multiply unsaturated mycolates were predominant. $N$. asteroides (GUH-2) nocardomycolate patterns were studied with respect to growth phase and the unsaturated mycolates were common in log phase but absent in stationary phase. These mycolates were also found to be significantly shorter in stationary phase and the degree of unsaturation may be correlated with the virulence of the isolate. ${ }^{36,37}$

Rhodococcal mycolates are typically 40 carbons in length, shorter than those of the Nocardia which average 50 carbons, although both species have $\alpha$ branches 12 to 18 carbons in length. ${ }^{18} R$. lentifragmentus mycolates have been widely studied. ${ }^{16,38}$ Field desorption mass spectrometry showed the mycolate population to range between 38 and 50 carbons with major components at 44, 46, and 48 carbons. These occur as both mono and dienoic mycolates containing saturated 12-14 carbon $\alpha$ branches. NMR analysis showed that the double bonds in the mero chain possessed cis stereochemistry. The $R$. lentifragmentus mycolates were separated by argentation TLC and quantified showing that $7.4 \%$ were fully saturated, $53.1 \%$ were monounsaturated, and $39.5 \%$ were diunsaturated mycolates. Similar studies on $R$. rhodochrous mycolates showed these to be $30 \%$ saturated with predominant 38,40 , and 42 carbon mycolates and $67 \%$ monounsaturated mycolates which were slightly larger at 40,42 , and 44 carbons. ${ }^{39}$ These studies quantify desaturation and chain length; however, as noted earlier, this is probably dependent on the precise culture conditions.

In the genus Gordona larger mycolates have been found which possess approximately 60 carbons with $1-4$ double bonds and $\alpha$ branches of 16 or 18 carbons. ${ }^{40,41}$ The recently defined genus Tsukamurella has 62-78 carbon mycolates with a 20-22 carbon $\alpha$ branch and up to six double bonds. ${ }^{42}$ The mycolates of these genera differ from those of mycobacteria in being highly unsaturated. There are other reports of anomalous mycolates from organisms similar to the Tsukamurella which may be reclassified as such: M. thamnopheos tetra and penta-enoic 72-78 carbon mycolates containing saturated 20 and 22 carbon $\alpha$ branches; ${ }^{12}$ G. aurantiaca with mycolates of 60-78 carbons, 2-7 double bonds and 18:1 or $20: 1 \propto$ branches $^{43}$ and M. fallax which contains a di- and tri-unsaturated 7078 carbon mycolates. ${ }^{14,44}$

\section{Structural Variation in Mycobacterial Mycolic Acids}

\section{Chemotaxonomy of Mycobacterial Species}

TLC analysis of mycolic acid distribution has been a valuable tool in the classification of various mycobacterial species. Both one and two-dimensional TLC methodology, employing a variety of solvents, has been used for chemotaxonomy. ${ }^{18,45,46}$ Comprehensive catalogues of TLC profiles demonstrating the classes of mycolates contained by various species have been compiled. ${ }^{19,47-49}$

More recently, high performance liquid chromatography (HPLC) has also been used to generate characteristic profiles of mycolates for many mycobacterial species and these have been used diagnostically. ${ }^{26,27,50-64}$ These methods have become so highly developed that the CDC in 1996 published a book entitled "Standardized Method for HPLC Identification of Mycobacteria" to facilitate the use in the clinical laboratory setting of mycolic acid HPLC patterns as a rapid diagnostic tool for speciating mycobacteria 
(Centers for Disease Control, U.S. Department of Health and Human Services, Public Health Service).

\section{Class Variation Between Species}

The mycolic acids of the Mycobacteria are among the longest and most highly functionalized of the mycolata. They occur with a wide variety of functional groups, both polar and non-polar, which give rise to the characteristic HPLC profiles discussed above used to identify them (Fig. 1 shows examples of many of these classes of mycolic acids). These modifications occur at two points in the mero chain, referred to as distal (closest to the $\omega$-end of the chain) and proximal (closest to the $\beta$-hydroxy acid). These two sites roughly divide the chain into thirds. The two exceptions to this general pattern are the shorter $\alpha^{\prime}$ mycolates and the $\omega-1$ methoxymycolates of some rapidly-growing species. Polar modifications tend to be restricted to the distal position and include such functional groups as methyl ethers, ketones, esters, and epoxides. Non-polar modifications occur at both the distal and the proximal positions and include cis or trans double bonds and cis or trans cyclopropanes. As noted above, trans functionalities have an adjacent methyl branch. The distribution of these mycolic acids in various mycobacterial species is detailed in Table 2.

The most widespread of the classes of mycolic acids are the $\alpha$ mycolates, which may contain double bonds or cyclopropanes in cis configurations or double bonds or cyclopropanes in trans configurations with an adjacent methyl branch. Every mycobacterial species which has been examined to date produces $\alpha$ myocolates. The next most widelydistributed class of mycolic acids are the ketomycolates. These are found in many different species, regardless of growth rate or status as pathogens or saprophytes. $\alpha^{\prime}$ and wax ester mycolates are also widely distributed, although they are notably absent from $M$. tuberculosis. Epoxymycolates are considerably more restricted in occurrence but neither growth rate nor pathogenic status correlates precisely with their distribution. Methoxymycolates appear, with five exceptions, to be present only in pathogenic species, and primarily in slow-growers. Interestingly, methoxymycolates in all cases appear to cooccur in species which also produce ketomycolate, a correlation which will be explored in more detail in the biosynthesis section of the review. The $\omega-1$ methoxymycolate species is the most restricted, occurring in a handful of pathogenic rapidly-growing strains that also produce epoxymycolate as their only other oxygenated type of mycolic acid, with the exception of M. alvei.

\section{Microheterogeneity}

Within a particular class of mycolic acids, there is considerable heterogeneity in the chain lengths of the individual acids. This is easily recognized by an inspection of the HPLC chromatogram shown in Fig. 2B and the FAB mass spectrum shown in Fig. 2C. The HPLC peaks are separated on the reversed-phase column due to two-carbon differences in their total chain length. These two-carbon differences can be attributed to variation in the length of both the mero branch and the $\alpha$ branch. The results from studies on $M$. tuberculosis and M. smegmatis mycolates will be described below. While they won't be discussed further here, it should be noted that studies of mycolic acids from several other mycolata species which demonstrate chain length heterogeneity have also been reported. These studies include the description of mycolates from $N$. asteroides ${ }^{35}$ M. fortuitum, ${ }^{101} M$. thamnopheos,${ }^{12} M$. microti,${ }^{91} M$. fallax,${ }^{14}$ and the oxygenated mycolates of M. fortuitum, M. farcinogenes, and M. senegalense. ${ }^{79}$

Pyrolytic GC/MS has been useful in studying the $\alpha$ branches of mycolic acids. In an analysis of total mycolates from 32 mycobacterial species by GC/MS, Kusaka and Mori $^{22}$ found that each species produced several different $\alpha$ branch lengths, which ranged from 20 to 26 carbons. Interestingly, five out of six strains which produced $\mathrm{C}_{20} \alpha$ branches were fast growing (with the single exception of $M$. leprae), while eight out of 
Table 2. Mycolate class variation among mycobacterial species

\begin{tabular}{|c|c|c|c|c|c|c|c|c|c|}
\hline Species & $\alpha-$ & $\alpha^{\prime}-$ & $\mathrm{M}$ & $\mathrm{K}$ & E & WE-OH & $\omega-1 \mathrm{M}$ & $\alpha-\mathrm{BR}$ & References \\
\hline \multicolumn{10}{|l|}{$\begin{array}{l}\text { Pathogenic slow } \\
\text { growers }\end{array}$} \\
\hline M. africanum & + & & + & + & & & & 26 & 70 \\
\hline M. asiaticum & + & & + & + & & & & 24 & 71,72 \\
\hline M. avium & + & & & + & & $+18,20$ & & (22), 24 & 70,72 \\
\hline M. bovis & + & & + & + & & & & (24), 26 & 70,72 \\
\hline M. bovis $B C G$ & + & & $+\mathrm{v}$ & + & & & & (24), 26 & $70,72-74$ \\
\hline M. branderi & + & & & + & & +20 & & 26 & 75,76 \\
\hline M. celatum & + & & & + & & $+20,(22)$ & & 24,26 & 77 \\
\hline M. conspicum & + & & & + & & $+18,20$ & & & \\
\hline M. farcinogenes & + & $+\mathrm{v}$ & & & + & & & 24 & $72,79,80$ \\
\hline M. genavense & + & + & & + & & & & & 81,82 \\
\hline M. haemophilum & + & & + & + & & & & $22,(24)$ & 83 \\
\hline M. heidelbergense & + & + & & + & & & & & 84 \\
\hline M. interjectum & + & & & + & + & + & & & 85 \\
\hline M. intermedium & + & + & & + & & & & & 86 \\
\hline M. intracellulare & + & & & + & & +20 & & (22), 24 & 70,72 \\
\hline M. kansasii & + & & + & + & & & & (22), 24 & $19,70,72$ \\
\hline M. lentiflavum & + & + & & + & & & & & 87 \\
\hline M. leprae $^{\mathrm{a}}$ & + & & $+\mathrm{v}$ & + & & & & 22,24 & $72,88-90$ \\
\hline M. lepraemurium & + & & & + & & $+\mathrm{v}$ & & $24,(26)$ & 72 \\
\hline M. malmoense & + & + & & + & & & & (24), 26 & 71 \\
\hline M. marinum & + & & + & + & & & & $24,(26)$ & 70,72 \\
\hline M. microti & + & & + & + & & & & 26 & 72,91 \\
\hline M. paratuberculosis & + & & & + & & + & & 24 & 70,72 \\
\hline M. scrofulaceum & + & & & + & & $+18,20$ & & (22), 24 & 70,72 \\
\hline M. shimoidei & + & + & & + & & +20 & & 24 & 70,71 \\
\hline M. simiae & + & + & & + & & & & (22), (24), 26 & $70-72$ \\
\hline M. szulgai & + & & + & + & & & & (22), 24 & 70,72 \\
\hline M. triplex & + & + & & + & & & & & 92 \\
\hline M. tuberculosis & + & & + & + & & & & (24), 26 & 70,72 \\
\hline M. ulcerans & + & & $+\mathrm{v}$ & + & & & & 24 & $70,72,93$ \\
\hline M. xenopi & + & & & + & & $+(20), 22$ & & (24), 26 & $8,70,72,94$ \\
\hline \multicolumn{10}{|l|}{$\begin{array}{l}\text { Nonpathogenic slow } \\
\text { growers }\end{array}$} \\
\hline M. cookii & + & + & & & & + & & 24 & 95 \\
\hline M. gastri & + & & + & + & & & & (22), 24 & 70,72 \\
\hline M. gordonae & + & & + & + & & & & (22), 24 & $19,48,70,72$ \\
\hline M. hiberniae & + & & & + & & $+18,20$ & & 22,24 & 96 \\
\hline$M$ & & & & & & & & & \\
\hline nonchromogenicum & + & & & + & & $+18,20$ & & (22), 24 & 72 \\
\hline M. terrae & + & & & + & & $+18,20$ & & (22), 24 & 70,72 \\
\hline M. triviale & + & & & & & & & (22), 24 & $70,72,97$ \\
\hline \multicolumn{10}{|l|}{$\begin{array}{l}\text { Pathogenic rapid } \\
\text { growers }\end{array}$} \\
\hline M. abscessus & + & + & & & & & & $(20,22), 24$ & 93 \\
\hline M. chelonae & + & + & & & & & & (22), 24 & $70,72,98,99$ \\
\hline M. fortuitum & + & $+\mathrm{v}$ & & & + & & $+\mathrm{v}$ & (22), 24 & $70,72,100-102$ \\
\hline M. mageritense & + & + & & & + & & & & 103 \\
\hline M. mucogenicum & + & & & & & $+18,20$ & & $(20), 22,24$ & 104,105 \\
\hline M. novacastrense & + & & & + & & + & & & 106 \\
\hline M. peregrinum & + & $+\mathrm{v}$ & & & + & & $+\mathrm{v}$ & (22), 24 & $72,100,102$ \\
\hline M. porcinum & + & $+\mathrm{v}$ & & & + & & $+\mathrm{v}$ & $(20,22), 24$ & $100,107,108$ \\
\hline M. senegalense & + & $+\mathrm{v}$ & & & + & & $+\mathrm{v}$ & 24 & $70,72,79,80$ \\
\hline \multicolumn{10}{|l|}{$\begin{array}{l}\text { Nonpathogenic } \\
\text { rapid growers }\end{array}$} \\
\hline M. agri & + & + & + & & & & & $(20,22), 24$ & 72,108 \\
\hline M. aichiense & + & & & + & & + & & 24 & 72,93 \\
\hline M. alvei & + & & & & & & + & 22,24 & 109,110 \\
\hline M. aurum & + & & & $+\mathrm{v}$ & & + & & 22,24 & $19,70,72$ \\
\hline M. austroafricanum & + & $+\mathrm{v}$ & & + & & + & & 22 & 93,109 \\
\hline M. brumae & + & & & & & & & 22 & 111 \\
\hline M. chitae & + & $(+)$ & & & + & & & $(20), 22,24$ & 72,112 \\
\hline$M$ & & & & & & & & & \\
\hline chlorophenolicum & + & & & + & & + & & & 113 \\
\hline M. chubuense & + & + & & $(+)$ & & + & & 22,24 & 72,93 \\
\hline M. confluentis & $(+)$ & & & + & & & & & 114 \\
\hline M. diernhoferi & + & & & + & & + & & (20), 22, (24) & 93 \\
\hline M. duvalii & + & + & & + & & + & & $22,(24)$ & 19,72 \\
\hline
\end{tabular}




\begin{tabular}{|c|c|c|c|c|c|c|c|c|c|}
\hline Species & $\alpha-$ & $\alpha^{\prime}-$ & M & $\mathrm{K}$ & $\mathrm{E}$ & $\mathrm{WE}-\mathrm{OH}$ & $\omega-1 \mathrm{M}$ & $\alpha-B R$ & References \\
\hline M. fallax & + & & & & & & & 22,24 & 14,97 \\
\hline M. flavescens & + & & & + & & $+18,20$ & & $(22), 24$ & $19,70,72$ \\
\hline M. gadium & + & & & + & & + & & 22,24 & 72,93 \\
\hline M. gilvum & + & + & & $(+)$ & & + & & (22), 24 & 72 \\
\hline M. hodleri & + & & & + & & $+18,20$ & & 22,24 & 115 \\
\hline M. komossense & + & & $+\mathrm{v}$ & + & & + & & 22,24 & 72,93 \\
\hline M. madagascariense & + & & & + & & + & & 22 & 116 \\
\hline M. moriokaense & $(+)$ & & & + & & + & & & 93,109 \\
\hline M. neoaurum & + & & & $(+)$ & & + & & (20), 22, (24) & 72 \\
\hline M. obuense & + & $+\mathrm{v}$ & & $(+)$ & & + & & $22,(24)$ & 19,117 \\
\hline M. parafortuitum & + & + & & $(+)$ & & + & & $(20), 22,(24)$ & $19,72,118$ \\
\hline M. phlei & + & & & $(+)$ & & + & & 22,24 & $19,70,72$ \\
\hline M. poriferae & + & $+\mathrm{v}$ & & + & & + & & & 109,119 \\
\hline M. pulveris & + & $+\mathrm{v}$ & & + & & + & & 22,24 & 93,109 \\
\hline M. rhodesiae & + & & & $(+)$ & & + & & 22,24 & 19,72 \\
\hline M. smegmatis & + & + & & & + & & & (22), 24 & 70,72 \\
\hline M. sphagni & + & & & $(+)$ & & + & & (22), 24 & $93,109,117$ \\
\hline M. thermoresistible & + & $+\mathrm{v}$ & + & + & & & & (22), 24 & $70,72,118$ \\
\hline M. tokaiense & + & & & $(+)$ & & + & & (22), 24 & $72,93,117$ \\
\hline M. vaccae & + & + & & + & & + & & 22,24 & $19,70,72$ \\
\hline M. valentiae & $(+)$ & $(+)$ & & $(+)$ & & + & & 22 & 19,118 \\
\hline
\end{tabular}

a, Methoxy-like component on acid methanolysis; + , component present; $(+)$, minor component present; $+\mathrm{v}$, may vary in quantity or be absent.

The abbreviations used are: $\alpha$-alpha; $\alpha^{\prime}$-alpha'; M-methoxy; K-keto; E-epoxy; WE-wax ester, numerical value represents the length of the secondary alcohol released upon saponification; $\omega-1 \mathrm{M}-\omega-1$ methoxy; $\alpha$-BR $-\alpha$-branch released upon pyrolytic cleavage of the mycolate.

References ${ }^{7,21,22,65-69}$ were all used to compile the pyroysis GC data in the table.

eight strains examined whose mycolates contained any $\mathrm{C}_{26} \propto$ branch were slow growers. Later, Kaneda and coworkers ${ }^{68}$ looked at the $\alpha$ branch chain lengths contained on each individual member of separated classes of mycolic acids from 21 mycobacterial species by GC/MS and found that smaller $\alpha$ branches are found on smaller mycolates. They also analyzed the chain length of the non-mycolate-associated fatty acids and found that in a general sense, the distribution of 22-, 24-, and 26-carbon fatty acids mirrored the distribution of $\alpha$ branch chain lengths from the same organism. M. smegmatis, for example, was found to contain 22 and 24 carbon fatty acids as well as mycolic acids with 22 and 24 carbon $\alpha$ branches. The ratio of 22 to 24 carbon fatty acids was roughly $20: 80$, while the ratio of 22 to 24 carbon $\alpha$ branches was 10:90 for $\alpha, \alpha^{\prime}$, and epoxy mycolates. These authors reported the presence of 22,24 , and 26 carbon fatty acids in $M$. tuberculosis in the proportions 13:17:70, respectively, yet the mycolates all contained 24 and 26 carbon $\alpha$ branches in approximately the same ratio of 10:90, with negligible amounts of 22 carbon $\alpha$ branch.

While $\alpha$ branch chain length variation can account for some of the heterogeneity seen in mycolic acids, the full range of variability can only be explained if the mero chain contains variability as well. In the M. tuberculosis $\alpha$ mycolate sample analyzed in Fig. 2, for example, variation in length of the $\alpha$ branch between 24 and 26 carbons would only result in two isomers instead of the six isomers observed. Very high temperature GC/MS and mass chromatography have been used to show that mycolates contain heterogeneity beyond what can be attributed to $\alpha$ branch differences. When either $\alpha$ mycolates as a whole were examined ${ }^{67}$ or when $\alpha$ mycolates were separated by argentation TLC into subclasses, ${ }^{69}$ a broad range of total carbon number species were detected. $\alpha$-Mycolates from $M$. smegmatis ranged from 74 to 81 carbons, while those from M. tuberculosis ranged from 76 to 86 carbons. ${ }^{67}$ In a survey of eight different species of M. smegmatis, Baba and coworkers ${ }^{120}$ analyzed the total carbon number for $\alpha^{\prime}, \alpha$, and epoxy mycolates. They report the total carbon numbers ranged from 60 to 66 carbons for $\alpha^{\prime}$ mycolates, 72 to 81 carbons for $\alpha$ mycolates, and 73 to 81 carbons for epoxymycolates. In contrast to $M$. smegmatis where the distribution of sizes were similar for $\alpha$ and epoxy, M. tuberculosis produces oxygenated mycolates which are longer than $\alpha$ mycolates. When the free acids 
of each mycolate class were examined by ESI-MS it was found that $\alpha$, methoxy, and keto had total carbon number distributions of 76-82, 83-90, and 84-89, respectively. ${ }^{121}$

Beyond this $\alpha$ branch and mero chain heterogeneity there is yet another layer of variability within mycolates of a single total carbon number that might be termed "microheterogeneity". By this we mean the permutations in the values of $\mathbf{a}, \mathbf{b}$, and $\mathbf{c}$ (see Fig. 1) which yield a population of mycolates all with the same total carbon number but with differences in the internal positioning of the functional groups. This microheterogeneity has been analyzed in detail for the $\alpha^{\prime}, \alpha_{1}$ and $\alpha_{2}$ mycolates of $M$. smegmatis. Gray and colleagues were able to isolate mycolates of each carbon length by reverse phase HPLC and then determine the values of $\mathbf{a}, \mathbf{b}$, and $\mathbf{c}$ by either trimethylsilylation and EI-MS, or by ozonolysis and subsequent chromatographic analysis. ${ }^{122,123}$ They found that for $\alpha^{\prime}$, a could be 17 or 19, while b could be 15, 17, 19, or 21. Not all permutations were observed, however, as they did not report $\mathbf{a}=17, \mathbf{b}=15$; or $\mathbf{a}=17, \mathbf{b}=21$. $^{122}$ The results were even more complex for $\alpha-1$ and $\alpha-2$ mycolates, where values ranged from 12 to 21 for $\mathbf{a}, 5-17$ for $\mathbf{b}$, and 13-22 for $\mathbf{c}$, although it must be noted that many of these values represent a mole fraction of less than $5 \% .^{123}$

This microheterogeneity contributes significantly to the total number of molecules contained in each "class" of mycolic acids. For example, in the M. smegmatis example studied by Gray and coworkers, about 100 structural isomers are present in the mixture of $\alpha$ myocolates in this species (at a mole fraction of 0.1 or higher). ${ }^{123}$ If the major classes of mycolates from $M$. tuberculosis each contain a similar number of structural isomers in the five major series ( $\alpha$, methoxy-cis, methoxy-trans, keto-cis, keto-trans) then there were approximately 500 total chemical compounds in the "saponified wax" samples first called "mycolic acid" by Professor Anderson in 1938.

\section{BIOSYNTHESIS OF MYCOLIC ACIDS}

\section{A. Mero and Alpha Branch Synthesis}

\section{Short-Chain Lipid Synthesis: the Alpha Branch and Mero Primers}

Fatty acid synthesis occurs through repetitive cycles of condensation, keto reduction, dehydration, and enoyl reduction. These steps are catalyzed by four key enzymatic activities (Fig. 3): $\beta$-ketoacyl synthase (KAS), $\beta$-ketoacyl reductase (KR), $\beta$-hydroxyacyl dehydrase (DE), and enoyl reductase (ER). ${ }^{124}$ The saturated fatty acid produced during a standard cycle of such anabolic reactions is used processively as the substrate for another condensation in the following round of elongation until a terminal extension value is attained. In general, two types of fatty acid-synthesizing systems exist. Most eukaryotes (except plants) contain large polyfunctional enzymes, known as Type I fatty acid synthase systems (FAS I), in which all of the above-mentioned enzymatic activities are encoded. These polypeptides are arranged so that the active sites are positioned by the folding of contiguous stretches of protein to yield the required catalytic domains in the proper sequence. ${ }^{125-128}$ Alternatively, FAS II systems, which occur in bacteria and plants, catalyze the various individual steps by discrete dissociable enzymes that function as a complete system. ${ }^{129-131}$ The reactions in fatty acid synthesis proceed by the same chemistry irrespective of the FAS type. In both cases substrate is continuously activated via a thioester linkage to the prosthetic group of either the required cofactor (acyl carrier protein or coenzyme A) or the enzyme complex KAS. ${ }^{129}$

The coupling of the growing chain, which is transiently attached to a cysteine at the KAS active site, with malonate to yield a $\beta$-ketoacyl product is the first step in elongation and is catalyzed by the KAS component of the FAS system. During the condensation malonate is attached to a thiol of a prosthetic phosphopantetheine. This prosthetic group is covalently attached to a serine residue of either an acyl carrier protein (ACP) in the case of the Type II FAS, or an ACP-domain in the Type I FAS system. The condensation occurs as a result of nucleophilic attack by the 2-carbon of the malonyl-ACP intermediate on the carboxyl carbon of the growing acyl chain. The $\beta$-ketone 
A.

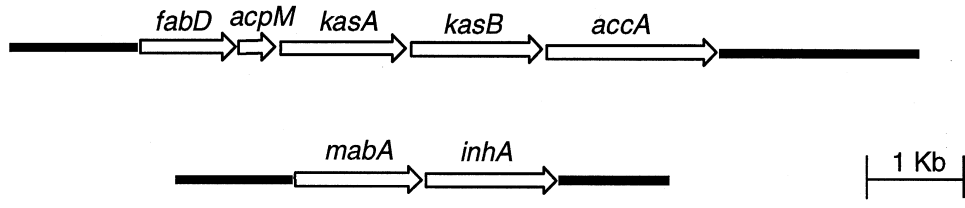

B.

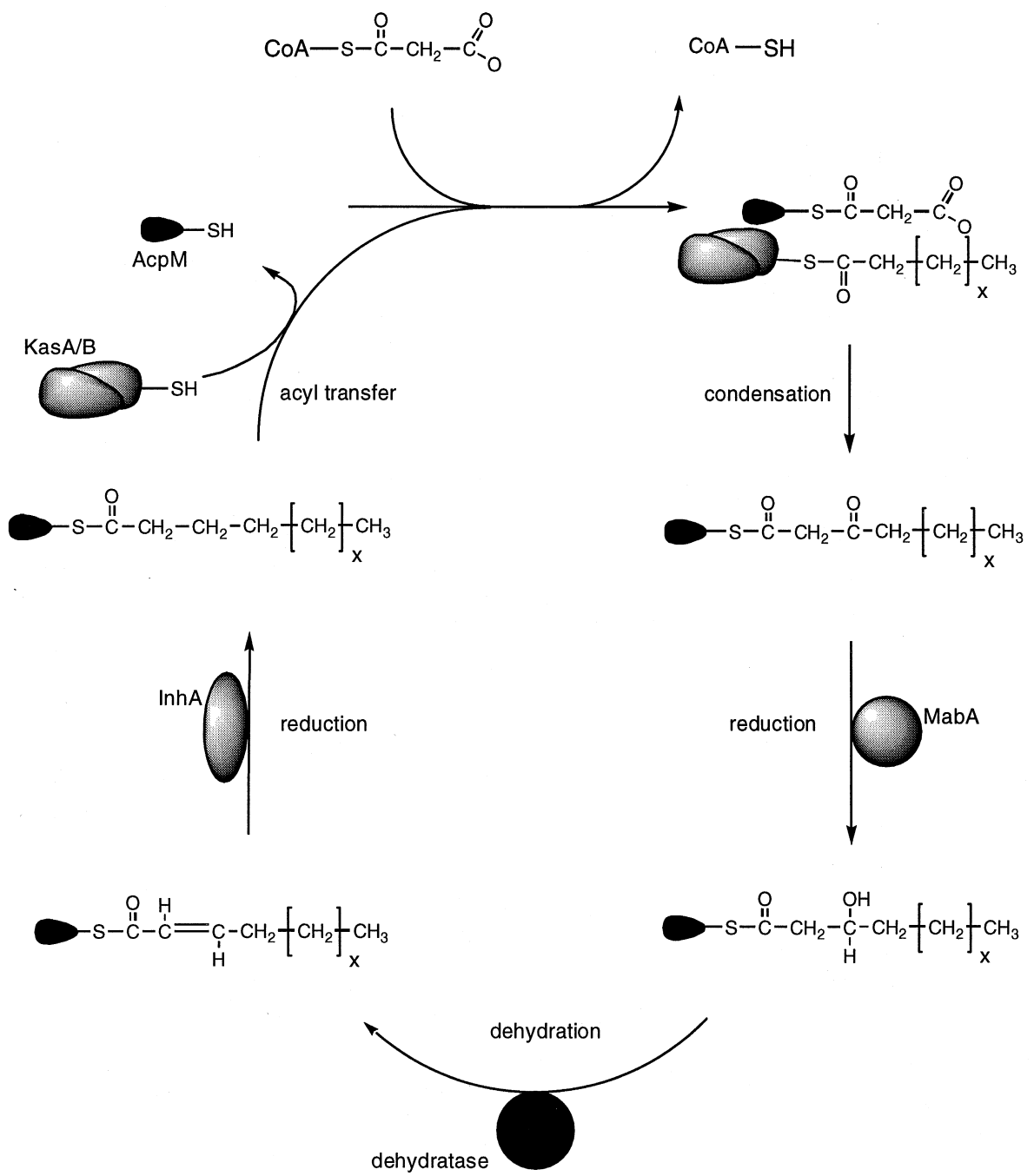

Fig. 3. The mycobacterial Type II FAS system which produces mycolic acids. (A) Genomic organization of the genes encoding proteins thought to be involved in mycolic acid biosynthesis identified through the use of isoniazid which interferes with their biosynthesis. (B) Functional roles of the various proteins involved in the biosynthesis of the meromycolate chain. All of the proteins involved are found in the two loci described above with the exception of the dehydratase whose identity is not known with certainty.

from the condensation is reduced to a secondary alcohol by the NADPH-dependent KR. The alcohol is then dehydrated by the DE activity to form the $\alpha, \beta$-unsaturated enoyl-ACP. ${ }^{132}$ The final basic reaction of fatty acid elongation is the reduction of the 
Table 3. Properties of the FAS I and FAS II systems from mycobacteria

\begin{tabular}{lcc}
\hline Property & FAS I & FAS II \\
\hline De novo synthesis & + & - \\
Palmitoyl CoA elongation & + & + \\
Elongation products & $\mathrm{C}_{26}-\mathrm{C}_{36}-(\mathrm{CoA})$ & $\mathrm{C}_{18}-\mathrm{C}_{50}-\mathrm{ACP}$ \\
Low ionic strength & inactivation & no effect \\
Nucleotide requirement & $\mathrm{NADPH} / \mathrm{NADH}$ & $\mathrm{NADPH}$ or NADH \\
MMP/MGLP & large stimulation & no effect \\
Limiting step & product dissociation & unknown \\
\hline
\end{tabular}

resulting trans $\triangle 2$-enoyl-ACP to a saturated hydrocarbon chain by the ER at the expense of a second molecule of NADPH. ${ }^{129,131,133}$

Mycobacteria are atypical with respect to FAS systems in that they possess both Type I and Type II systems. Basic characteristics of these two mycobacterial FAS systems are compared in Table 3. Extensive characterization of fatty acid synthesis in M. smegmatis has demonstrated that the role of FAS I in mycobacteria is to perform de novo synthesis of fatty acids from acetate. ${ }^{134}$ This is largely based on the detection of transacylase activities which load the acetate or growing acyl chain to the prosthetic group of the $\beta$ ketoacyl synthase domain and malonate to the endogenous ACP-like prosthetic group, and the identification of fatty acids that are extended by one or more $\mathrm{C}_{2}$ units. ${ }^{135}$ The FAS I system produces acyl chains that apparently peak at 16 and 24 carbons in length in a bimodal distribution attached to coenzyme A. ${ }^{136,137}$ The gene encoding this unusually large system has been cloned and sequenced from $M$. tuberculosis revealing that the order of the catalytic domains resembled a head-to-tail fusion of the two yeast FAS subunits. ${ }^{138}$

An interesting peculiarity of the mycobacterial FAS I system is the alteration in the distribution of the acyl products by mycobacterial-specific polysaccharides. The active mycobacterial polysaccharides are 3-O-methylmannose-containing (MMP) and 6-Omethylglucose-containing (MGLP) polysaccharides which show high-affinity binding of acyl-CoA esters of fatty acids. ${ }^{136,139,140}$ These polysaccharides alter fatty acid distribution by facilitating dissociation of a 16 carbon product acyl-CoA from its proteinassociated site, and promoting the synthesis of $\mathrm{C}_{16}$ fatty acids rather than $\mathrm{C}_{24}$.

Early studies on the Type II fatty acid synthase of mycobacteria revealed it to be analogous to other bacterial FAS II systems, with the notable exception of primer specificity. The mycobacterial FAS II system is unable to perform de novo synthesis from acetate; rather, it has a unique elongating activity, preferentially extending palmitoylCoA to a mixture of homologous acids ranging in size from 18 to 30 carbons. ${ }^{135,136}$ More recently, extensive work with cell-free extracts of $M$. tuberculosis has demonstrated that such extracts are capable of synthesizing very long chain fatty acids from malonate using various primers including acetate (primary products $16,18,24$, and 26 carbons in length) and palmitate (primary products monounsaturated 26, 28, 30, and 32 carbons in length). ${ }^{141}$ Presumably, these latter reactions are catalyzed by the same Type II system described in M. smegmatis by Bloch and colleagues previously.

\section{Long-Chain Lipid Synthesis: the Mero-INH Connection}

The synthesis of mycolic acids has been extensively studied for two decades, yet the enzymatic machinery responsible is just now being conclusively identified. Meromycolic acids are biosynthesized by the stepwise condensation of acetate units in a normal headto-tail sequence typical of fatty acid synthesis in general. Growth of $M$. tuberculosis in the presence of $\left[1-{ }^{13} \mathrm{C}\right]$ - and $\left[2-{ }^{13} \mathrm{C}\right]$-acetate and subsequent examination of the ${ }^{13} \mathrm{C}-\mathrm{NMR}$ pattern of purified mycolic acids revealed the expected labeling pattern with no sign of $\mathrm{C}-\mathrm{C}$ coupling in isolated $\alpha$, methoxy, and ketomycolates (C. E. Barry, III, unpublished data). This result suggests that the biosynthetic pathway from palmitate is composed of 
a series of condensations of malonyl-CoA units onto this primer, rather than head-tohead type condensations of smaller subunits.

By examining the lipid metabolic steps affected by isoniazid (INH) treatment of $M$. tuberculosis, Takayama and coworkers first demonstrated that INH specifically inhibits the biosynthetic pathway leading to the formation of mycolic acids. ${ }^{142,}{ }^{143}$ These studies showed that treatment with low concentrations of INH for short periods of time resulted in the accumulation of saturated hexacosanoic acid and that this accumulation perfectly paralleled the inhibition of mycolic acid synthesis. Recently we have shown that this hexacosanoic acid accumulates bound to the acyl carrier protein of the Type II FAS system described above. ${ }^{144}$ The possibility of multiple Type II systems has now been effectively excluded by an analysis of the complete genome sequence of this organism. The lethal effect of INH on mycolic acid synthesis appears to involve the covalent cross-linking of ACP and KAS, two components of this Type II system, with a covalent bridge of INH. ${ }^{144}$ This study has identified a five gene operon which appears to be responsible for the elongation of the short chain fatty acid precursors to the mero-mycolate moiety. Isolation of the ACP from cells which had not been INH treated has revealed that this ACP is capable of carrying the growing fatty acid chain to the size of the full-length mero acid.

The locus discussed above is composed of five genes all transcribed in the same direction (Fig. 3A). Based on the fact that all five genes are very closely spaced, these genes probably represent a single transcript and may exhibit translational coupling. The first $\mathrm{ORF}$ in the operon encodes an enzyme with significant homology to FabD, which is a malonyl-CoA:ACP acyl transferase. ${ }^{130}$ FabD transacylates ACP to form malonyl-ACP, which can be used by a KAS system in extension of a growing fatty acid chain. The second ORF of this operon encodes the acyl carrier protein, termed AcpM. Acyl carrier proteins are necessary components involved in the elongation of fatty acids by carrying the growing acyl chain from reactive center to reactive center of each lipogenic enzyme. The recognition of fatty acids as substrates by the catalytic enzymes of the Type II pathway is dependent on them being tethered to an ACP. ${ }^{124}$

The uniqueness of this five gene operon is evident from the third and fourth open reading frames. They both encode $\beta$-ketoacyl synthases (KasA and KasB), and two such genes adjacent to one another in a FAS II locus has not been previously reported. Ketoacyl synthases have been shown in E. coli to control chain length. ${ }^{124}$ This system should be compared with the Type II aromatic polyketide synthases (PKS) which biosynthesize metabolites such as actinorhodin and tetracycline. The mycobacterial system appears similar to these types of systems in some aspects of its organization (reviewed recently by Hopwood ${ }^{145}$ ). These PKS systems are observed in many actinomycetes and show clustering of an ACP and KAS as a common motif. A second enzyme generally follows the KAS which is highly homologous but does not contain several important amino acids typical of the KAS active site motifs. Although their precise function is unknown, these homologs have been termed "chain-length factors" and their presence is required for aromatic polyketide synthesis and may determine the number of polyketide addition cycles catalyzed by the system. These proteins are thought to function by complexing with the KAS and modifying its activity in some way. In the mycobacterial system, however, the KAS homolog referred to as KasB appears to be a functional enzyme and has all of the conserved amino acids required for this function. Whether these two proteins can function independently on separate subsets of chain lengths or together to yield full length meromycolate is unknown at present. There also remains the formal possibility that the role of these two enzymes is to create 26 to 30 carbon primers for extension by another system. Inspection of the genome of $M$. tuberculosis does not reveal any likely candidates for extension other than Type I polyketide synthases, and none of these appear to have the correct domain structure. Still, confirmation of this unique very long chain extension activity awaits definitive proof by in vitro assays of the purified enzyme components. The fifth ORF of the multi-gene operon encodes an enzyme 
involved in carboxylation of acetyl coenzyme A, which activates acetate to malonate, the primary substrate of the KAS. ${ }^{130}$

In addition to the enzymes encoded in the AcpM region, three primary genes are missing from this operon whose products are required to complete the fatty acid synthesis cycle. These are the ketoreductase (KR) responsible for the production of the $\beta$-hydroxyl intermediate, the dehydratase (DE) that catalyzes the elimination of water from this intermediate to give the 3-trans enoyl fatty acid, and the enoyl reductase (ER) that produces the final saturated fatty acid. Candidates for the two reductases (dubbed InhA and MabA) have also been identified through studies with INH resistance in M. smegmatis and both are located in a second operon (Fig. 3). ${ }^{146-149}$ One of these, InhA, has been quite controversial as a target for INH but has been characterized well as an enoyl-ACP reductase. ${ }^{150}$ Upstream of the gene encoding InhA is a second gene, apparently co-transcribed in pathogenic mycobacteria, designated mabA which is likely to encode the KR activity involved in the mycobacterial Type II FAS system. Although a definite gene encoding the dehydratase component involved in mycolic acid synthesis has not been conclusively identified yet, an analysis of the genome reveals numerous dehydratase-like coding sequences.

Thus, one scenario for the biosynthesis of the intact meromycolate chain is the processive addition of multiple malonate units using the enzymatic machinery outlined above and consisting of FabD, AcpM, KasA, KasB, AccB, InhA, and MabA. In this scenario, the intact $48-54$ carbon meromycolate chain is produced from 16 to 26 carbon precursors generated by the Type I FAS, and the preformed mero chain is then functionalized. One alternate hypothesis, that desaturation and elongation occur simultaneously or in a step-wise fashion with interrupted cycles of addition and reduction, is considered below but seems inherently less plausible because of the difficulty in controlling the positions of the desaturation in such a simple FAS system. There also exists the possibility that the $\mathrm{KasA} / \mathrm{B}$ elongation system only catalyzes elongation to a certain terminal value and then the primer is transferred to one of many Type I systems which are present. This possibility is difficult to exclude but the observation of very long (50 carbon) precursors attached to an ACP argues against this strongly. ${ }^{144}$

\section{B. Meromycolate Modification Reactions}

\section{The Desaturation}

The introduction of functional groups to the mero chain is thought to begin with desaturation of the saturated alkyl chain to yield two cis double bonds (one at the distal position and the other at the proximal position), which can be further modified as necessary. There are two main hypotheses for the manner in which the double bonds are introduced into the meromycolate chain: (1) formation of the full-length saturated mero acid followed by the introduction of double bonds by aerobic terminal desaturases, and (2) extension of unsaturated fatty acid precursors and/or the introduction of the distal double bond by a dehydration during fatty acid synthesis.

There exists substantial evidence that desaturation of the mero chain occurs prior to condensation with the $\alpha$ branch. Takayama and coworkers ${ }^{141}$ found that a cell-free extract of $M$. tuberculosis could synthesize from malonate fatty acids as long as 56 carbons which contained various numbers of double bonds. Further support for the notion that desaturation is coupled to elongation comes from several reports of the identification of unsaturated and cyclopropanated fatty acids shorter than full-length mero chain with the appropriate spacing between these functional groups to be precursors of the full-length mero acid (see, for example, Refs ${ }^{151-154}$ ). These findings offer strong support that desaturation occurs during elongation, although it is important to bear in mind that the activities observed in crude cell-free extracts could be unrelated to meromycolate synthesis and that the observed functionalized long-chain lipids could easily be the result of lipid catabolism. Feeding experiments with unsaturated long chain mycolate precur- 
sors are difficult to evaluate because of the nature of the cell-free system used and the extremely low-level incorporation of label (see Section II.D).

The fact that Gray and coworkers ${ }^{123}$ identified several values for the internal fragments $\mathbf{a}, \mathbf{b}$, and $\mathbf{c}$ in the $\alpha$ myocolates of $M$. smegmatis, but only in certain combinations (never, for example, did they find the smallest $\mathbf{a}$, smallest $\mathbf{b}$, and smallest $\mathbf{c}$ together on the same mycolate), suggests that desaturation occurs after mero chain elongation, and that certain rules apply to the placement of double bonds. If desaturation were to occur during elongation, one would expect the placement of double bonds to display a Gaussian distribution, which would result in all combinations of $\mathbf{a}, \mathbf{b}$ and $\mathbf{c}$. We have further shown that AcpM-attached mero-length fatty acids are unsaturated and serve as substrates for other modification reactions (see Section II.B.2).

Alternatively, the desaturation may be introduced during elongation by a specific $\beta$ hydroxyacyl-ACP dehydrase ( $\alpha$ fabA-like gene product). In E. coli, the pathway leading to unsaturated fatty acids under anaerobic conditions diverges at the point at which a fabA-like $\beta$-hydroxyacyl-ACP dehydrase introduces a double bond into a 10 carbon intermediate. ${ }^{124}$ This $\beta$-hydroxydecanoyl-ACP dehydrase is distinct from the $\beta$-hydroxyacyl-ACP dehydrase which participates in the general elongation reactions in that it catalyzes the dehydration of $\beta$-hydroxydecanoyl-ACP to a mixture of trans-2-decanoylACP and cis-3-decenoyl-ACP. Instead of suffering reduction by an ER, this double bond is preserved and the cis-3-decenoyl-ACP intermediate is further elongated as an unsaturated fatty acid. A specialized KAS called FabB catalyzes the next elongation reaction in unsaturated fatty acid biosynthesis which the normal synthase cannot. ${ }^{124,129}$ It is possible that either KasA or KasB in M. tuberculosis possesses a FabB-like activity and operates specifically on an unsaturated very-long-chain precursor. Arguing against such a pathway is the lack of any enzyme in the genome of $M$. tuberculosis with significant homology to FabA. The only homologs of FabB (in fact, the only dissociable ketoacyl synthases in the genome) are the two enzymes described above, KasA and KasB.

Mechanistically, it seems much more likely that the desaturations of the meromycolate, whether coupled to elongation or not, occur through the action of an aerobic terminal mixed function desaturase. These enzymes catalyze the oxidation of a saturated fatty acid into an unsaturated fatty acid in many organisms with the simultaneous oxidation of NADPH and the reduction of molecular oxygen. Interestingly, while there appear to be no homologs of the vertebrate or yeast enzymes (which act on CoA esters) in the M. tuberculosis genome, there are clear homologs of the plant enzymes (which act on ACP-bound fatty acids). ${ }^{155}$

\section{Modifications Involving Methyl Transfer from SAM}

Experiments in which mycobacteria are grown in the presence of labeled methionine indicate that the methyl group of methionine can become incorporated directly into mycolic acids. By the incorporation of either $\left[{ }^{14} \mathrm{C}-m e t h y l\right]$ methionine or $\left[{ }^{3} \mathrm{H}-m e t h y l\right]$ methionine in growth media, it has been shown that the bridging methylenes of the cyclopropane rings, the carbon of the methoxy functionality, and the methyl branches adjacent to trans-olefins, methoxy and keto moieties are all derived from methionine, presumably via S-adenosyl- $L$-methionine (SAM). ${ }^{15,101,123,156-158}$

While it had long been proposed that the meromycolyl cyclopropane groups were derived from double bonds (for a discussion, see Refs ${ }^{159,160}$ ), the first direct evidence for this idea came with the identification of a gene from M. tuberculosis capable of conferring upon $M$. smegmatis the ability to produce large amounts of cyclopropane containing mycolic acids. ${ }^{161}$ This gene, coined cmal for cyclopropane mycolic acid synthase (CMAS-1), was found to be $34 \%$ identical to the E. coli cyclopropane fatty acid synthase (CFAS). ${ }^{160,162}$ It was shown by argentation TLC and NMR of the hybrid mycolate produced in $M$. smegmatis that CMAS-1 introduced a cyclopropane at the distal position. CMAS-1 showed strong homology to other SAM-dependent methyl transferases, particularly in the region known to actually bind SAM. 
Based on the sequence of cmal, a second gene from $M$. tuberculosis, cma2, was identified. The corresponding protein, CMAS-2, was shown to introduce a cyclopropane ring at the proximal position again by characterization of the purified chimeric mycolate obtained following heterologous expression in M. smegmatis. ${ }^{20}$ Interestingly, this enzyme will cyclopropanate the $\alpha_{1}$ but not the $\alpha_{2}$ mycolates from $M$. smegmatis, suggesting that the enzyme has a specificity for cis double bonds. M. tuberculosis, however, produces both cis and trans cyclopropane-containing mycolates, ${ }^{163}$ yet $\mathrm{cmal}$ and $\mathrm{cma} 2$ produce only cis-cyclopropanes. This observation suggests the existence of at least one more enzyme in $M$. tuberculosis, capable of producing trans cyclopropanes. The trans series of cyclopropanes are always accompanied by an adjacent methyl branch, suggesting that two equivalents of SAM are involved in their formation; the first to form a trans olefin with an adjacent methyl group, and the second to form the actual cyclopropane ring. Indeed, an analysis of the recently completed genomic sequence of $M$. tuberculosis reveals two additional homologs of $\mathrm{cmal}$ and $\mathrm{cma} 2$ which might encode such activities.

Remarkably, a cluster of four more genes was identified in M. tuberculosis by DNA hybridization to a cmal probe. ${ }^{164}$ All four genes were similar to each other in addition to cmal and cma2. By introducing these genes into $M$. smegmatis either singly or in combination and analyzing the resultant mycolates, it was shown that mma4 encodes an enzyme which introduces a hydroxyl group with an adjacent methyl branch at the distal position, while the mma3 gene product methylates this hydroxyl to form a methyl ether. The newly formed mycolate species were identical to the methoxymycolate and ketomycolate series from M. tuberculosis ${ }^{164}$ (and the characterization was repeated in slightly more detail in Ref. ${ }^{165}$ ). Curiously, mma2 encodes a cyclopropanation enzyme similar to $c m a 2$ in that it modifies the proximal position. The reason for this apparent duplication of function is unclear. One hypothesis is that CMAS-2 cyclopropanates the $\alpha$ series while MMAS- 2 cyclopropanates the oxygenated series of mycolates. The introduction of mmal into $M$. smegmatis appeared to have no effect; however, overexpression of mmal in M. tuberculosis resulted in a marked increase in the amounts of trans substituents at the proximal position. ${ }^{121}$ The appearance of both trans cyclopropanes and trans double bonds, both with adjacent methyl branches in the mmal overexpressing strain led to the conclusion that mmas- 1 converts the proximal cis double bond to a trans double bond with an allylic methyl branch. Trans cyclopropane formation would then have been catalyzed by the endogenous enzyme present in limiting quantities in $M$. tuberculosis.

The addition of an allylic methyl branch, with the concomitant conversion of cis to trans olefin, could result in two different products, depending on which side of the double bond methyl addition takes place. For example, in the $\alpha$ myocolates of $M$. marinum, M. ulcerans, and M. smegmatis which contain a trans olefin with an adjacent methyl branch at the proximal position, this methyl branch is located on the $\mathrm{COOH}$ side of the double bond, not the $\omega$ side. $^{15,123}$ However, in M. tuberculosis, the methyl branches found adjacent to methoxy and keto mycolates (which presumably are formed from $\alpha$-methyl trans precursors) are found on the $\omega$ side of the oxygenated group. ${ }^{163,165}$ When Minnikin and Polgar ${ }^{166}$ analyzed $\alpha$ myocolates from $M$. tuberculosis they concluded that the methyl branch adjacent to cyclopropanes at the proximal position were located on the $\omega$ side of the cyclopropane. Thus, it may be that $M$. tuberculosis adds methyl branches on the $\omega$ side, while strains such as $M$. marinum, M. ulcerans, and $M$. smegmatis add methyl branches on the $\mathrm{COOH}$ side.

If the transformation of a cis double bond to a trans olefin with an adjacent methyl branch proceeds as proposed in Fig. 4 for the action of MMAS-1, then the trans double bond migrates one carbon away from its original location in the cis substrate. From the mechanism proposed for MMAS-1-like action, it should be expected that the precursor cis mycolate would have a b spacing one carbon larger. However, analysis of the major values for $\mathbf{b}$ reported for $\alpha_{1}$ and $\alpha_{2}$ mycolates in $M$. smegmatis ${ }^{123}$ reveals just the opposite trend: the majority of $\alpha_{1}$ mycolates have smaller $\mathbf{b}$ values than those of $\alpha_{2}$. One potential explanation of this conflict is that MMAS-1-like enzymes which produce $\alpha_{2}$ 


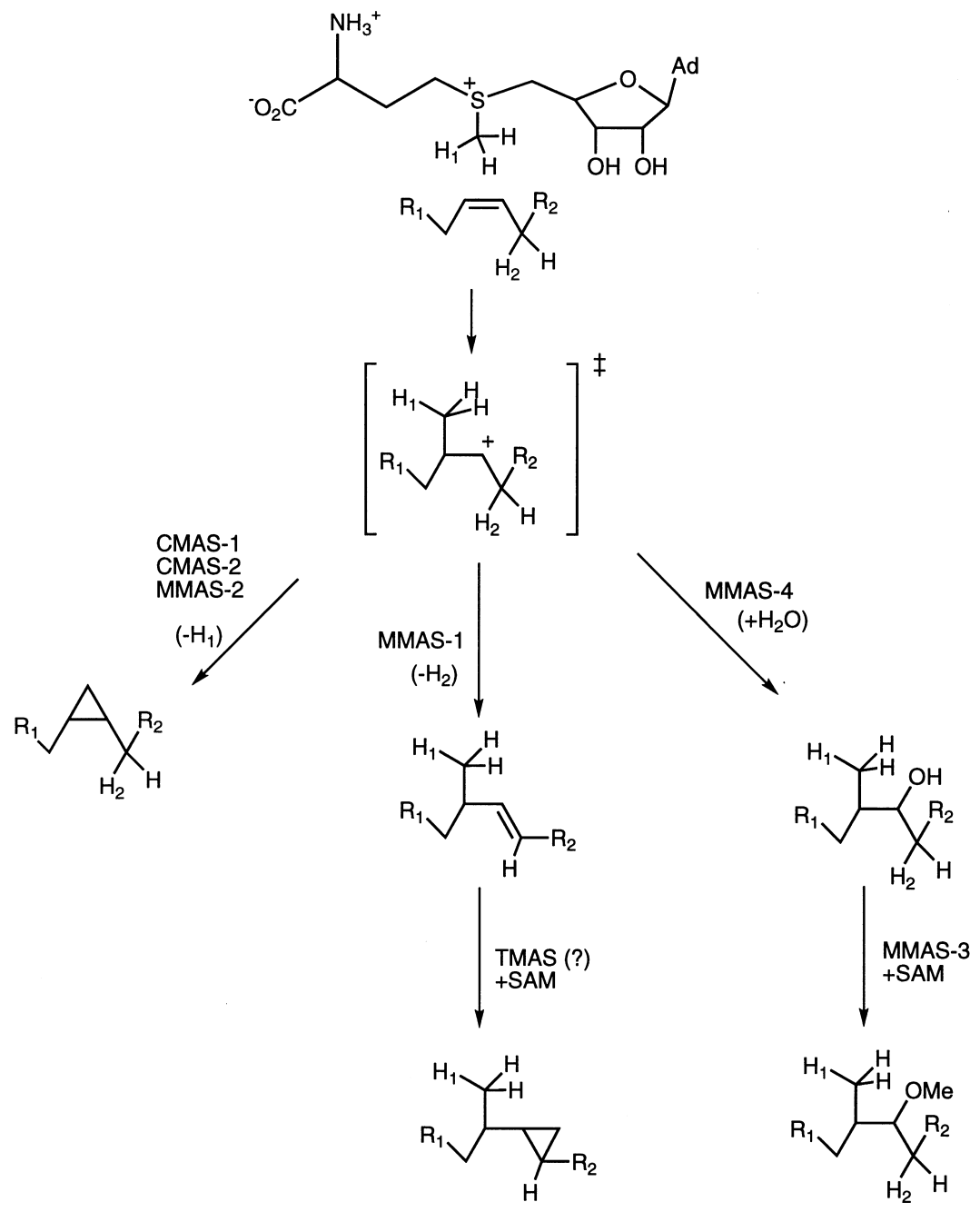

Fig. 4. The common cationic intermediate involved in functionalization of the meromycolate chain and its decomposition to yield the various substituents found in mycobacterial mycolic acids. Addition of a methyl group from SAM generates the carbonium ion shown which can then be deprotonated to form a cycopropane ring or a trans olefin with an adjacent methyl branch. The trans olefin could be the substrate for a second SAM-dependent methylation to form the trans cyclopropane series seen in the oxygenated mycolates of $M$. tuberculosis. The cation can also react with water to form the hydroxymethyl mycolate precursor to keto and methoxymycolates.

mycolates have a preference for longer $\mathbf{b}$ values; hence only the remaining, smaller $\mathbf{b}$ values are seen in the $\alpha_{1}$ series.

Other workers have identified the same mma gene cluster from M. bovis BCG (strain Pasteur), but reached surprisingly different conclusions about the function of these genes. ${ }^{167}$ A BCG genomic cosmid library screened in M. smegmatis for the production of oxygenated mycolates resulted in the discovery of these same four genes, which the authors named $\operatorname{cmaDCBA}$. The same pattern of oxygenated mycolates was produced when all four genes or just cmaA (which corresponds to mma4 in M. tuberculosis) was introduced into $M$. smegmatis, while cyclopropanated mycolic acids were lost when any of several deletions were introduced. The conclusion was that $\mathrm{cmaA}$ is responsible for making hydroxy and keto mycolates, while $c m a D, c m a C$ or $c m a B$ might be the cyclopropanating enzyme. ${ }^{167}$ The differences between these two studies lay primarily in the choice of starting organisms; Dubnau and colleagues chose a strain of BCG which fails to produce methoxymycolates. Sequence comparisons of the O-methyl transferase mma3 from 
M. tuberculosis with the corresponding gene ( $\mathrm{cmaC}$ ) from BCG (Pasteur) revealed the presence of multiple amino acid alterations in this sequence. Cloning of the mma3 gene from $M$. tuberculosis into this strain of BCG restored the ability to synthesize methoxymycolate (Yuan, Y., Barry, C. E. III, manuscript submitted). Another major difference in these studies was in the interpretation. Dubnau and colleagues proposed that the $\mathrm{CmaA}$ protein resulted in the formation of a free diffusible carbon-centered cation which then required a separate "hydrase" activity to form the observed hydroxymycolate, while we proposed a unifying hypothesis allowing the chemical outcomes of all of the methyl transferases to be rationalized (Fig. 4). This proposal centers around the generation of an unstable common cationic intermediate (which remains bound in the active site of the methyltransferase for its short lifetime) which can decompose in a number of ways to yield the observed modified meromycolate products. Such a hypothesis was first proposed in chemical terms by Lederer in 1969 to explain the relation between various observed sterol metabolites. ${ }^{159}$ Strong support for the intermediacy of a common cationic intermediate is found in the extremely high degree of identity observed between the various members of this methyl transferase family, suggesting common binding sites for SAM, and similar active sites.

This family of methyltransferases (including CFAS) differs from enzymes which transfer a methyl group to other substrates in having a conserved tryptophan residue central to one highly conserved motif which is involved in SAM binding (PGMTLLDIGCGWG). Because of recent speculation that cation- $\pi$ interactions ${ }^{168}$ are important in stabilizing such cationic intermediates, it is tempting to speculate that this tryptophan is involved directly in active-site contact with the intermediate cation. Resolution of this issue awaits the solution of the three-dimensional structure of one of these enzymes.

Although heterologous expression of these enzymes has been extremely useful in elucidation of their function, such experiments are inherently unsatisfying in the sense that they do not identify the actual substrate upon which the methyl group addition takes place. Cell-free conditions have been developed for the determination of activity based on radiomethyl group addition from SAM to a meromycolate precursor (Yuan, Y., Mead, D., Schroeder, B., Barry, C. E. III, J. Biol. Chem. 1998 (in press). These studies have revealed that the substrate for methyl transfer is an extremely long lipid approximately the size of the full-length meromycolate chain (50-56 carbons) attached to a proteinaceous cofactor. The recent identification of the AcpM protein as a potential carrier for meromycolate synthesis allowed the demonstration that this protein was, in fact, the carrier for the cyclopropanation reaction. Affinity-purified antisera to the C-terminus of the AcpM protein was capable of inhibiting these methyl transfer reactions in $M$. tuberculosis cell-free extracts.

\section{Oxidative Modifications of the Meromycolate}

Various oxidative modifications of the meromycolic acid chain occur to produce the wide variety of functional groups found in full-length mycolates. These include the reactions which form keto, epoxy, wax ester, and $\omega-1$ methoxymycolate. Unfortunately, relatively little is known about either the enzymology or the genetics of these transformations. The biosynthesis of ketomycolate and methoxymycolate are intimately linked through the common hydroxymycolate precursor which is the product of the action of the MMAS-4 enzyme. The ratio of these two mycolates is also controlled in some fashion through the geometric nature of the proximal center since overexpression of MMAS-1 (which introduces the allylic methyl branch resulting in trans olefin formation) also results in an increase in the amount of ketomycolate produced. ${ }^{121}$ Methoxymycolate quantity seems to be limited, in part, by the level of the MMAS-3 enzyme, since overexpression of this enzyme results in the complete absence of ketomycolate and its replacement by methoxymycolate (Yuan et al., manuscript submitted). While Dubnau et al., ${ }^{167}$ report CmaA produces both hydroxy and keto mycolates in $M$. 
smegmatis, our work with mma4 suggests this gene encodes an enzyme which converts a distal double bond to a hydroxyl with an adjacent methyl branch. ${ }^{164}$ We have been unable to reproduce the production of ketomycolate when using only mma4-transformed M. smegmatis although we have noted a profound instability of such constructs due to the dramatic effect of hydroxymycolate production and inhibited growth rate. It seems possible that the ketomycolate production observed in this strain was the result of upregulation or mutation of an endogenous non-specific oxidase. In M. tuberculosis there is presumably a specific oxidase whose function is to convert hydroxymycolate into ketomycolate, although the ability to easily alter keto and methoxy mycolate production suggests either that this oxidase is not very active or is poorly expressed.

It seems reasonable to expect that epoxy mycolates also have an unsaturated precursor, although there has been no report of an epoxy-producing enzyme to date. While trans functionalities are most often seen at the proximal position, Minnikin et al. ${ }^{79}$ reported the identification of an unusual trans epoxy mycolate in M. fortuitum with an adjacent methyl branch to the distal side of the epoxy. This epoxide might therefore come from a trans olefinic precursor made by an mmal-like enzyme in $M$. fortuitum with specificity for the distal cis double bond. Such a precursor has been identified in $M$. fallax. ${ }^{14}$ It would be interesting to see if the same type of mycolate also exists in $M$. fortuitum.

The wax ester mycolates are thought to be derived from keto mycolates via the biological equivalent of a Baeyer-Villiger oxidation. ${ }^{169}$ Support for this proposal came from the demonstration that molecular ${ }^{18} \mathrm{O}_{2}$ could be incorporated into the ester oxygen, suggesting a monooxygenase-like transformation. ${ }^{170}$ As a less likely alternative, an alcohol could be esterified to a dicarboxylic acid in the reverse of the wax ester hydrolysis reaction. Recently, a gene was identified from an Acinetobacter calcoaceticus mutant which fails to make short-chain wax esters. ${ }^{171}$ The gene, acr 1 , is believed to be an acylCoA reductase which forms an aldehyde product. This aldehyde can then be reduced to an alcohol and esterified to a second acyl-CoA. There is a convincing homolog of this gene (orf2) in M. tuberculosis immediately adjacent to the coding sequence for CMAS- 1 . This same set of enzymatic reactions was observed in extracts of M. tuberculosis, which could catalyze the reduction of palmitoyl-CoA to hexadecanol, and subsequently esterify this to yield hexadecyl palmitate and hexadecyl stearate. ${ }^{172}$ However, neither wax ester mycolates nor the dicarboxylic acid precursor has been reported in M. tuberculosis.

It is tempting to speculate that the precursor to the $\omega-1$ methoxy functionality is a terminal double bond. Interestingly, a small amount of a trimethylsilylated derivative indicative of a terminal double bond was found in an analysis of mycolates from $M$. smegmatis. $^{122}$ The mechanism of $\omega-1$ methoxymycolate formation must differ from that of methoxymycolate formation since the $\omega$ - 1 methoxy group contains no adjacent methyl branch, and hence cannot be the product of an MMAS-3, MMAS-4-like process.

\section{The Condensation and Carriers}

The mechanism by which the $\beta$-hydroxy acid moiety is assembled has been the subject of intense speculation mostly centering around the apparent head-to-head condensation of two fatty acid precursors in the biological equivalent of a Claisen condensation. $4,173,174$ The primary evidence for this type of mechanism was the early work of Gastambide-Odier and Lederer in Corynebacterium diptheria. ${ }^{175,176}$ These workers showed that the relatively simple 32-carbon corynomycolates were biosynthesized by a simple head-to-head condensation of two 16 carbon precursors. $\left[1-{ }^{14} \mathrm{C}\right]$-palmitate was incorporated into both the 1 and 3 positions of the corynomycolate. It has been observed that pathogenic JK group Corynebacteria when grown in Tween 80 containing media scavenge the oleic acid from the tween and incorporate these fatty acids directly, forming 36 carbon mycolates with $\omega-9$ double bonds in both $\alpha$ branch and mero chains. ${ }^{177}$ It has also been noted that mycolic acids may play a role in the resistance of Corynebacteria group D2 strains to lipophilic drugs. ${ }^{178}$ 
Subsequent work has established that this general concept holds true for more complex mycolates such as those found in other members of the mycolata including N. asteroides and $M$. smegmatis. ${ }^{10,179}$ Interestingly, when $M$. smegmatis was grown in the presence of $\left[1-{ }^{14} \mathrm{C}\right]$ tetracosanoate, the label was incorporated only into the terminal carbonyl carbon, not the 3-position. ${ }^{157}$ Since the major $\alpha$-branch of $M$. smegmatis is 24 -carbons in length, this result suggests that this 24-carbon precursor is not an efficient primer for the Type II system which constructs the mero branch of the mycolate.

The simple corynebacterial system has continued to be the most tractable for the study of the enzymology of this process with several reports of the cell-free synthesis of a 3-keto-corynomycolate (the dehydrocorynomycolate). ${ }^{180-182}$ These workers reported that the dehydro product was in the form of an ester of trehalose but trehalose does not appear to be required for, nor is it stimulatory to, the cell-free activity ${ }^{180,183,184}$ and such esters of the dehydrocorynomycolate are rapidly degraded back to palmitic acid. ${ }^{185}$ The nature of the carrier immediately following the condensation remains unclear. Datta and Takayama characterized a phospholipid which contained dehydrocorynomycolate from large-scale cell-free incubations but were unable to conclusively identify this material. ${ }^{186}$ Following up on this observation Besra et al. characterized a presumably related phospholipid from $M$. smegmatis whole cells which was found to have a complex structure consisting of a mannosyl-P-polyprenol with an attached mycolic acid at the 6 position of mannose which was called Myc-PL. ${ }^{187}$ Importantly, this compound has not been identified with the corresponding 3-oxo-smegmamycolate attached so the inferred relationship to the PL-1 compound of Datta and Takayama and therefore the relationship to the condensing activity is less than certain. Labeled mycolate attached to this molecule is incorporated into various mycolate-containing materials (primarily trehalose mono-mycolate) including the the cell wall-bound fraction (less than 6\%). The definitive identification of the carrier following condensation awaits the development of a purified condensing enzyme system. Mycolate metabolism through trehalose remains a complex issue. The recent demonstration that the well known "antigen 85" complex enzymes possess transesterification activity for trehalose-bound mycolate suggests that the shuffling of such lipids among several different ester linkages to cell-wall associated molecules is quite facile. $^{188}$

Whatever the carrier following condensation, it is clear that there must be two carriers prior to condensation. Mechanistically, the carbonyl carbon of the mero acid must act as an electrophile while the $\alpha$-carbon of the $\alpha$-branch must act as a nucleophile. Acylthioesters are known to have much more acidic $\alpha$ carbons than are the corresponding acyl oxygen esters. For example, the $\alpha$ hydrogen of S-acetoacetyl-N-acetylthioethanolamine has a $\mathrm{pKa}$ of 8.5 while the corresponding hydrogen on ethyl acetoacetate has a $\mathrm{pKa}$ of 10.5 (for a good discussion of this effect see pp. 741-776 in Ref. ${ }^{189}$ ). Thus, there is a 100 -fold increase in acidity of this proton due to the thioester. Other enzymatic examples of Claisen-type condensations (including malate and citrate synthases) which have been studied utilize a thioester as the nucleophilic partner and a $\beta$-keto carboxylic acid as the electrophilic partner. In the case of the putative mycobacterial condensing system one would thus predict that the $\alpha$ branch prior to condensation would be in the form of a thioester and that the immediate product of the condensation would also have this form. Thus the oxygen-containing trehalose esters or MycPL seem unlikely candidates for the carrier. Presumably considerations about the nucleophilicity of this carbon led to the proposal that the $\alpha$ branch was transiently carboxylated prior to the condensation reaction. Early results showing avidin inhibition of cell-free corynomycolate formation ${ }^{180}$ fueled this speculation although these results were not obtained by other workers. ${ }^{183}$ Recent feeding studies using 2,2-dideutero-palmitate show that in the isolated corynomycolate three deuteriums are retained, two at the 4 position and one at the 2 position. ${ }^{30}$ While this result does not rule out an intermediate carboxylation, it does suggest that enolate formation following carboxylation is unlikely, unless the deuterium is retained at the active site. Nonetheless, there is little reason to propose an intermediate 
carboxylation as simple enolate formation from a thioester is both mechanistically reasonable and precedented.

A working model for the biosynthetic steps which convert acetic acid into full-length mycolic acids in M. tuberculosis is shown as Fig. 5. Many of these steps and the enzymes which catalyze them remain highly speculative and this should be considered simply as a proposal for the biosynthetic pathway.

\section{Cell-Free "Complete Mycolate” Synthesizing Systems}

Several authors have reported on the existence of a particulate enzyme system which possesses the full range of enzymatic activities required for converting acetate into mycolic acids from $M$. aurum and $M$. smegmatis. ${ }^{190-194}$ Curiously, these particulate preparations are often incapable of incorporation of malonate or malonyl-CoA and are assayed instead with $\left[{ }^{14} \mathrm{C}\right]$ acetic acid. Typically, these systems are extremely inefficient and give only very low-level incorporation of radioactivity. Prepared in our laboratory and analyzed by electron microscopy, such cell-free systems are primarily composed of

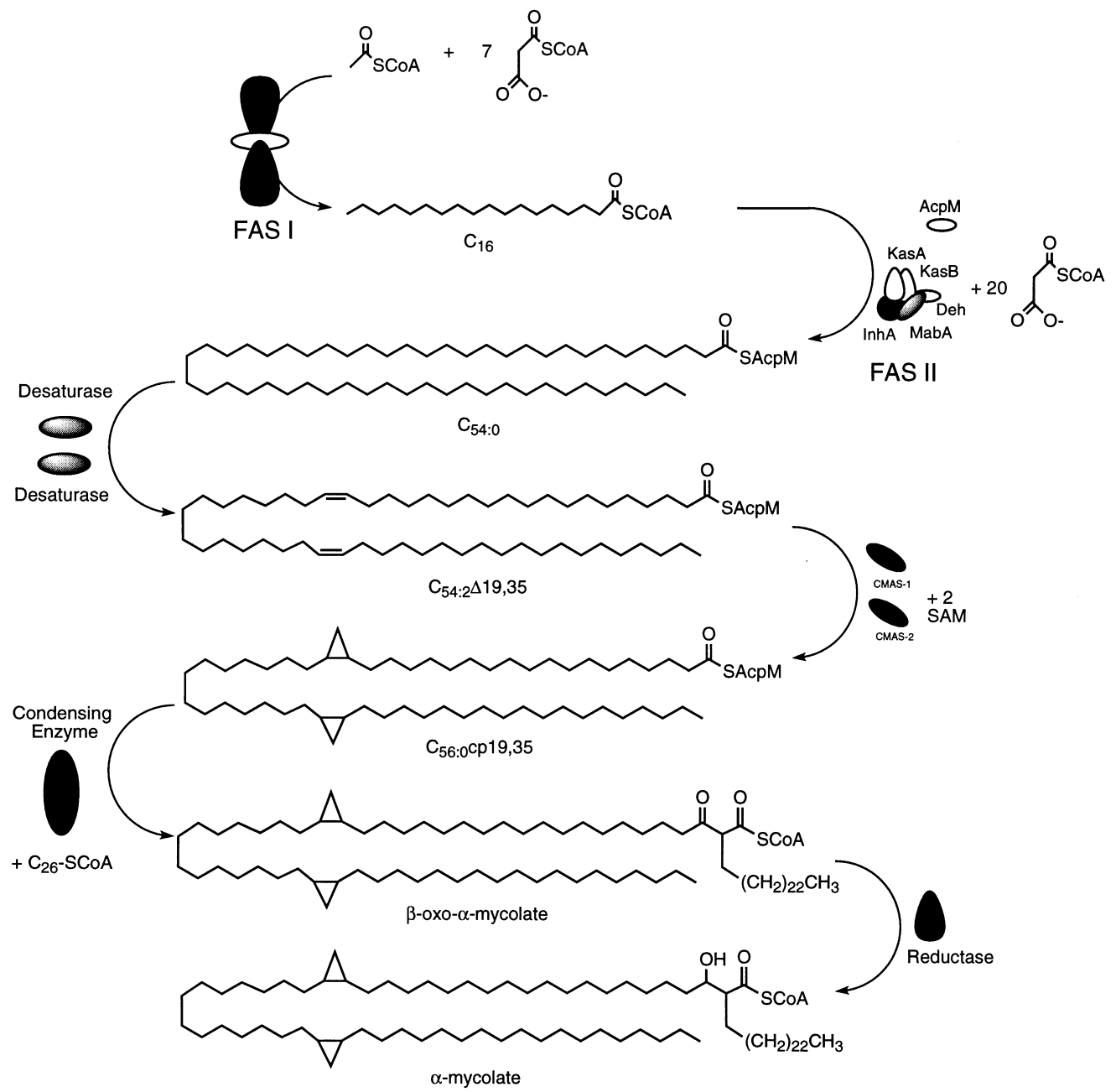

Fig. 5. A working model for the biosynthesis of a mycolic acids in M. tuberculosis. Production of 16 or 26 carbon precursors attached to coenzyme A by the Type I FAS system is followed by extension by the Type II system described in Fig. 3 to the full 54 carbon length of the mero acid. This is then subjected to two desaturations, cyclopropanation by the methyl transferases described in Fig. 4 and condensation with a thioester-bound $\alpha$ branch to form the 3-oxomycolate species which is then reduced to the 3 -hydroxy acid. 
nicked and damaged whole cells, clearly not just the particulate components of the cell (Slayden, R. A., Barry, C. E. III, unpublished results). Although such preparations have compromised viability in many cases they appear to have some residual cytoplasmic components by electron microscopy; therefore their status and usefulness as true cell-free systems is questionable. In addition, we have been unable to demonstrate inhibition of mycolate methylation reactions using water-soluble analogs of SAM such as sinefungin and S-adenosyl- $L$-homocysteine which are nonetheless very inhibitory to such reactions using cell-free preparations of these enzymes (Yuan, Y., Mead, D., Barry, C. E. III, unpublished results). Finally, the cell-free synthesis of long-chain fatty acids from 30 to 56 carbons in length previously described, which is most likely due to the meromycolateproducing Type II FAS system described above, was in a soluble, not particulate, enzyme system. ${ }^{141}$ In addition, all of the methyl transferases and the other enzymes now known to be associated with mycolic acid synthesis, such as KasA, KasB, AcpM, FabD, InhA, and MabA are soluble proteins and would be unlikely to have associated strongly with the system described (Mdluli, K., Slayden, R. A., Barry, C. E. III, unpublished results). Considering all of these factors this activity is difficult to explain as anything other than the incorporation of acetate by partially fragmented whole cells. Even if "cellfree" is an accurate description of such systems, they are sufficiently complex that their study does not give any significant benefit over the study of whole cells and the dramatic loss of activity that accompanies their preparation is a significant disadvantage. The development of efficient, truly cell-free systems remains a significant challenge to the field of mycolic acid biosynthesis.

\section{PHYSIOLOGICAL FUNCTION OF MYCOLIC ACIDS}

\section{A. General Features and Functions of the Cell Wall of Mycolic Acid Containing Bacteria}

In addition to the normal barrier functions of a cell wall skeleton involved in maintaining a rigid cell shape and turgor pressure against the variable osmolarity of the surrounding environment, mycobacteria and related genera possess many unique characteristics which are directly attributed to the presence of mycolic acids in their cell wall. ${ }^{4,195}$ The more important characteristics conferred by this structure include properties such as resistance to chemical injury, low permeability to hydrophobic antibiotic substances, ${ }^{196}$ resistance to dehydration, and the ability to persist and thrive within the hostile environment of the macrophage phagolysosome. ${ }^{197-199}$

Mycobacteria as a group are extremely impermeable to hydrophilic molecules, including nutrient molecules such as glucose, glycerol, as well as antibiotics such as $\beta$-lactams. The magnitude of this permeability difference between mycobacteria and other bacteria was first demonstrated conclusively in $M$. chelonei which was estimated to be between one and ten thousand fold less permeable to such substances compared with more typical organisms like E. coli. ${ }^{200}$ Subsequently this massive difference in permeability to hydrophilic molecules has also been shown to be a property of $M$. smegmatis ${ }^{201}$ and $M$. tuberculosis. $^{202}$ Given the conserved nature of the cell wall and structures of mycolic acids present across species of mycobacteria, this low permeability to hydrophilic solutes and extremely hydrophobic surface is likely to be a property common to the genus. ${ }^{203-205}$

Another familiar property related to the low permeability of mycobacterial cell walls is the ability of these organisms to retain coloration with certain water-soluble triarylmethane dyes upon acid treatment of intact stained bacteria ("acid-fast staining"). ${ }^{206}$ This property is also directly related to the exclusion of acid by the extremely hydrophobic intact cell wall of these bacteria. ${ }^{207}$ These types of physical properties would more commonly be associated with spores of other bacteria, and many or all of these macroscopic properties are a direct consequence of the physical organization of mycolic acids in the cell wall of this group of organisms.

The penetration of small hydrophilic molecules through the outer cell wall of mycobacteria is independent of their hydrophobicity and is presumably mediated by the pre- 
sence of a porin-like molecule in the cell wall. Such a pore-forming activity has been found in purified cell walls of $M$. chelonei and M. smegmatis ${ }^{201,208}$ and has been studied in lipid bilayer membrane preparations. ${ }^{209}$ Biochemical evidence suggests that there is only one porin, which is apparently present in low abundance or is extremely inefficient and is cation-selective, at least in $M$. chelonei. Interestingly, the complete genomic sequence of $M$. tuberculosis shows very few homologs of such channel-forming proteins, although one in particular is a close homolog of the Porin F protein of Pseudomonas aeruginosa $^{210}$ and may represent the pore active in the outer cell wall of mycobacteria. Although difficult to measure directly, providing the appropriate microenvironment for the pore to anchor and function is another important aspect of the hydrophobic domain of the mycobacterial cell wall.

\section{B. Structure of the Mycobacterial Cell Wall}

\section{Electron Microscopic Examinations}

Electron microscopy has provided many valuable clues as to the overall organization of the components of the mycobacterial cell wall (various aspects of cell wall structure have been reviewed recently in $\operatorname{Ref}^{203,211,212}$ ). Early studies using conventional transmission electron microscopy of ultrathin sections of various species of mycobacteria have shown two prominent electron-translucent zones, one immediately subtending the cytoplasm of the cell and presumably attributable to the plasma membrane, and another wider zone outside of this layer which has been attributed to the lipophilic domain of the cell wall. ${ }^{213}$ A typical thin section obtained by such techniques on $M$. avium is shown in Fig. 6A. ${ }^{214}$ More sophisticated techniques such as freeze-substitution have revealed essentially similar patterns with the added extension of the outermost electron-translucent layer to variable depths depending upon the details of the fixation process. ${ }^{215-217}$ The precise molecular composition of this outer electron-transparent layer is unknown with certainty but is thought to contain primarily covalently-attached mycolic acids at the base. The hydrophobic nature of the mycobacterial cell wall prevents fixation so the resolution of these techniques is limited to the covalently-associated cell wall core. The dehydration procedures used typically show abundant artifacts, additional artifacts also result post-resin imbedding involving cell shrinkage, and both of these factors make the outer layer of the wall difficult to define precisely. Freeze-fracture microscopic techniques have been informative as well and have revealed that the major plane of cleavage lies in the middle of the outer electron-transparent layer, the putative mycolic acid-containing cell-wall. A second plane of cleavage occurs within the hydrophobic region defined by the plasma membrane. ${ }^{206}$ These results support the existence of a hydrophobic subdomain of the outer cell wall containing lipids arranged in such a way as to generate a physical discontinuity in resistance to shear stress, consistent with a membrane bilayer.

We have recently established a definitive correlation between the presence of mycolic acids in the outer layer of $M$. avium and the appearance of the outer electron-transparent layer which substantiates the mycolic acid origin of this ultramicroscopic feature (Fig. 6B, ${ }^{214}$ ). M. avium is about 100 -fold less susceptible to the effect of isoniazid than is M. tuberculosis. Since isoniazid primarily affects the biosynthesis of mycolic acids in the cell-wall, and both species possess similar mycolic acids we sought to determine the molecular basis for this inherent resistance to this widely used antibiotic. We discovered that M. avium behaves similarly to $M$. tuberculosis with respect to the rate at which isoniazid penetrates the cell wall but that this organism reacts differently to deprivation of mycolic acids. M. avium appears to be capable of growth in the absence of continued synthesis of cell wall bound mycolic acids, resulting in a permeabilization of the outer cell wall membrane. Electron microscopic examination of organisms grown in low concentrations of isoniazid revealed that they no longer display the characteristic outer electron transparent layer (Fig. 6B). 


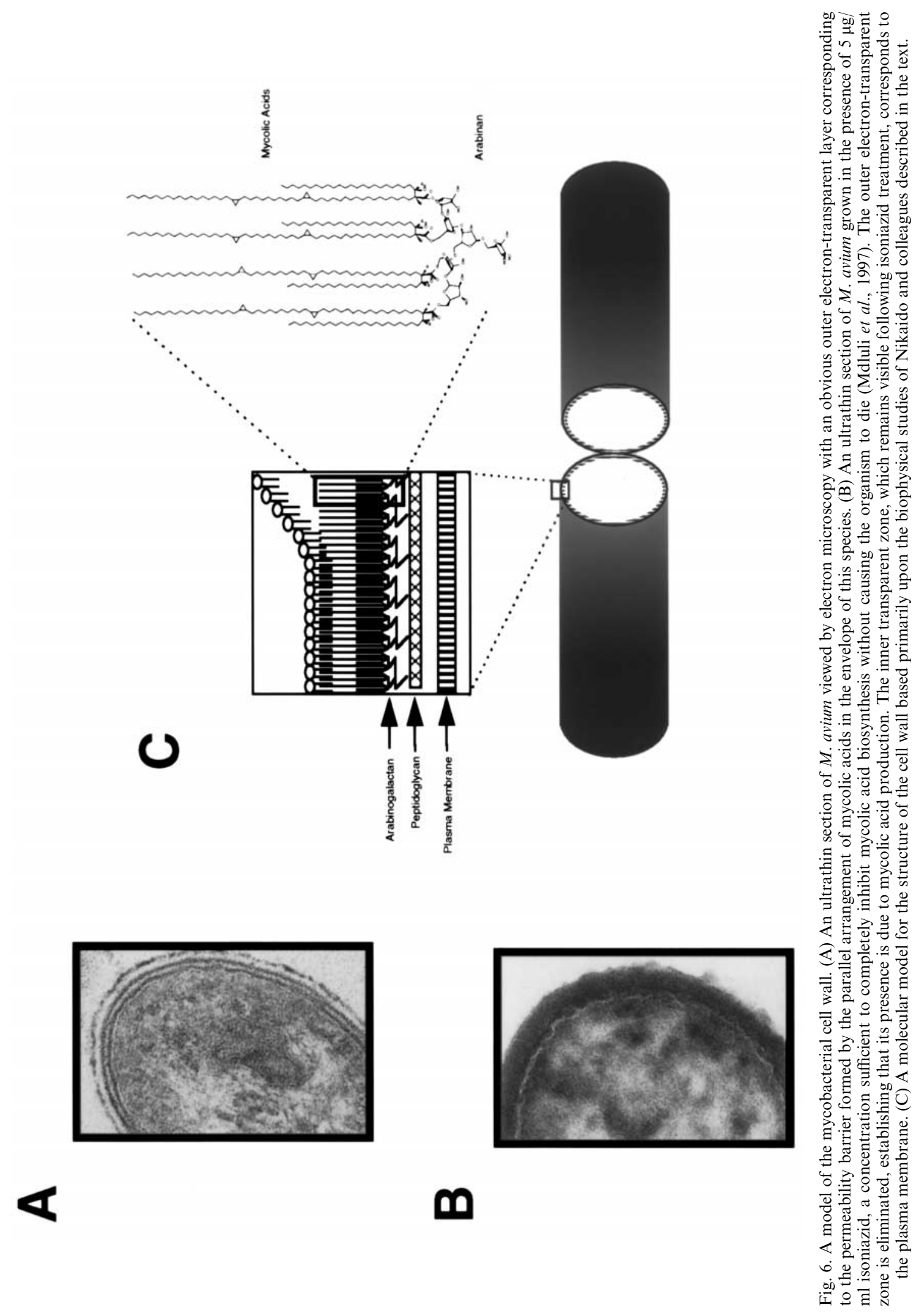




\section{Model of the Mycobacterial Cell Wall}

Many different models for the organization of the component structures of the mycobacterial cell wall have been proposed. The current model has been reviewed extensively recently and the intellectual underpinnings of this will only be briefly highlighted here for the purposes of establishing a context for the role of various mycolic acids in this structure. Excellent recent reviews include. ${ }^{203,211,212,218}$ The earlier models were primarily based upon three things; first, the ultrastructural data summarized above; second, quantitation of the amount of mycolic acid present in cell wall skeletons of delipidated bacteria; and third, chemical intuition regarding plausible interactions of the various components of the covalently attached cell wall matrix. The isolated cell wall contains three heteropolymeric subunits composed of peptidoglycan, arabinogalactan (a complex heteropolymer composed primarily of arabinose and galactose), and mycolic acids. The currently accepted model of cell wall structure relegates the peptidoglycan and arabinogalactan polymers largely to providing a scaffold for attaching and orienting mycolic acids in a direction perpendicular to the plane of the cell surface (Fig. 6C). In this conceptualization, the mycolic acids are aligned with the $\alpha$ branch and mero branch closely associated on the cusps of somewhat flexible penta-arabinosyl terminal units to form the inner leaflet of an asymmetric membrane bilayer. The outer leaflet of this bilayer is poorly defined but appears to consist primarily of short-chain fatty acids (from 15-19 carbons in length) mostly in the form of triacylglycerides. These apolar fatty acids exist in an approximately 2:1 ratio (of acyl chains) with mycolic acids in purified cell walls of M. chelonei. ${ }^{203}$ In addition to triacylglycerides, other more polar lipids such as phosphatidylinositolmannosides are found in purified cell walls. These lipids may also be associated with more extensive hydrophilic extensions (e.g. LAM) or loosely surface-associated materials (e.g. neutral polysaccharides). This outer leaflet may also be the site of attachment of various molecules such as sulfatides which have been implicated in host cell interactions. $^{219}$

\section{Biophysical Examinations of Cell Wall Structure}

The ability to rigorously define the physical organization of the components of the cell wall has been extremely limited because of the difficulty of separating and purifying this structure away from contaminating plasma membrane components. This was first accomplished convincingly by Nikaido and colleagues who analyzed purified cell walls by X-ray diffraction and observed a sharp reflection at $4.2 \AA$ suggesting that the major lipid components of these samples exist in a highly-ordered state resembling a frozen lipid bilayer. ${ }^{220}$ These studies were extended by measurement of the thermal properties of purified, protein-free cell walls using differential scanning calorimetry. In these studies, cell walls of $M$. chelone $i$ were found to have amazingly high phase transition temperatures at about 30 and $60^{\circ} \mathrm{C} .{ }^{221}$ This high-temperature phase transition strongly supports the X-ray diffraction studies in suggesting that at ambient temperature the bulk of the hydrophobic domain of the cell wall is in a highly-ordered state. The presence of two transition temperatures in mycobacterial walls suggests that the mycolate-containing outer layer has much lower fluidity than the cytoplasmic membrane, and at physiological temperatures, this layer is in a gel-like state which contributes to the low permeability of the cell wall. Some of the characteristics of this phase transition can be seen using purified mycolic acids aligned at an air-water interface. ${ }^{222}$ In addition, this phase transition can be seen in cell walls which have been stripped of protein and non-covalently associated small molecules by detergent extraction and in whole cells without any treatment. The temperature at which this phase transition occurs rises in direct proportion to the overall complexity of the sample, with free mycolic acids melting lowest, then detergentextracted cell walls, and finally purified cell walls and whole organisms melting at the highest temperature. ${ }^{222}$ This effect suggests that the covalently associated matrix of peptidoarabinogalactan serves a scaffolding function, enhancing the interaction of the mycolic 
acids and increasing the stability of the cell wall. The phase transition increases by about $20^{\circ} \mathrm{C}$ in comparisons of free mycolates with cell wall bound mycolates. Further studies have elaborated on this observation by examining the insertion of spin-labeled fatty acid probes into the hydrophobic domain of purified cell walls by ESR. ${ }^{221}$ These experiments demonstrated that the cell walls decreased in fluidity the deeper the probe was inserted, suggesting that the domain of lowest fluidity was the innermost portion of the hydrophobic region.

It is important to emphasize the very special properties of this membrane system in comparison to other biological membranes. Typical biological membranes are considered fluid mosaics with lateral mobility but with restricted vertical mobility, because the composite lipids are amphipathic. ${ }^{223}$ Solvation of the hydrophobic portion of the chain in water is energetically unfavorable, therefore these molecules associate together in a lateral continuum with only their polar head groups in contact with the aqueous exterior. Contrast this with the mycobacterial cell wall which is covalently anchored to the plasma membrane through intermediate complex carbohydrates such as arabinogalactan and peptidoglycan. Obviously, the covalent attachment of the polar lipid head groups in this system results in the removal of one degree of freedom from the system, lateral mobility. This enhances the impermeability of the cell wall since hydrophilic ions are typically transported across cellular membranes by the formation of asymmetric thinning defects in the membrane allowing small polar molecules to be internalized with their solvating counterions. ${ }^{224}$ In the absence of lateral movement such defects may be substantially less common and the wall will be much less permeable to such molecules than a fluid bilayer composed of equivalent lipids. This is reflected in the very high phase transition of the bulk of the mycolic acid in the cell wall which is significantly higher than the growth temperature of the organism. Therefore the bulk of the cell wall at growth temperature is not fluid in any sense. We have also observed considerable variation in intensity and temperature of this transition in comparing actively-growing cells with stationary phase cells with actively growing cells appearing to have lower temperature thermal phase transitions of lower intensity (Barry, C. E. III, unpublished). This suggests that non-growing cells may have a more tightly-organized cell wall and is consistent with many of the known microbiological characteristics including exceptionally long survival times in the absence of growth (latency). This restricted lateral mobility also raises the possibility that the cell wall inner leaflet is inhomogeneous with respect to mycolic acid composition, small pockets or bands of defined mycolic acids may exist and remain separated spatially by virtue of their covalent attachment to the underlying polysaccharide. Scanning electron micrographs of mycobacteria and related organisms show a distinct cylindrical appearance and the lip of such cylinders seems a likely place for a distinct zone of $\alpha$ mycolic acid subtype.

\section{Physiological Roles of Structural Variation in Cell-Wall Bound Mycolic Acids}

\section{Generic Properties of Mycolic Acids}

Mycolic acids possess unique characteristics essential for their physiological roles in maintaining the cell wall structure of mycobacteria and related genera. In addition to the obvious $\alpha$-alkyl branch, these features include the presence of the $\beta$-hydroxy functionality in the correct stereochemical configuration. The role of the hydroxyl group has been addressed most carefully in studying phase transition temperatures and compression isotherms of glucose and trehalose esters of various corynomycolic acids and derivatives. ${ }^{225}$ A direct comparison of the deoxy-corynomycolate containing esters with the normal hydroxy containing parent molecules revealed that the presence of the hydroxy group modulates both the phase transition temperature and the molecular packing of these molecules, with the deoxymycolate possessing a significantly higher temperature phase transition. Presumably this effect is a direct result of destabilization of an $\alpha$-branch mero-branch aligned conformation through hydrogen bonding between the hydroxyl 
proton and the nearby carboxylate oxygen. Further support for the role of this conformation in modulating packing of the alkyl chains comes from the same study in a comparison of the naturally-occurring erythro $(2 R, 3 R)$ isomer ${ }^{11}$ with the unnatural threo isomer of corynomycolate obtained synthetically. In this study the natural erythro isomer displayed the lowest phase transition temperature, followed by the intermediate threo isomer and then the highest melting deoxymycolate. ${ }^{225,226} \mathrm{~A}$ similar effect would be anticipated in the context of mycolic acids esterified to arabinose in the cell wall.

\section{Cis/Trans Olefins and Thermal Adaptation}

The most stable conformation of a linear, unbranched, saturated fatty acid is all trans with no gauche interactions of any adjacent methylenic hydrogens. Introduction of one olefinic moiety into such a chain has a negative effect on the ability of that chain to pack with other fatty acids in a lipid bilayer. If that olefin is $c i s$, a permanent elbow of about $120^{\circ}$ is introduced; if trans, the angle is less acute and the fatty acid has a correspondingly greater ability to pack tightly. Two cis double bonds do not affect the overall direction of the lowest energy conformation but instead introduce a bulge or curve into the lipid, shortening its overall length. Methyl branching has a similar effect; it disrupts tight packing and introduces a bulge.

In general, functionalities at the proximal position are thought to interact in the region of the cell wall of lowest fluidity and are usually either an olefin or a cyclopropane, in either a cis or trans configuration. All of the trans configurations (in either olefin or cyclopropane) are accompanied by an adjacent methyl branch. This position is thought to play a prominent role in maintaining the viscosity of the cell wall at an appropriate level. $100 \%$ of either cis or trans configuration at the proximal position has not been found in any species of mycobacteria, suggesting that the proper ratio of cis/trans and its regulation is important for this bioactive lipid membrane.

Homeoviscosity has been proposed to be an important property of biological membranes both from the perspective of control of fluidity and in terms of the activities of integral membrane proteins whose function must be preserved. The hallmark of homeoviscous adaptation is the induced variation of lipid structure in response to changes in growth temperature. ${ }^{227}$ There are two attributes of mycolates which appear to be regulated to adapt to changing growth temperature: the length of the meromycolate and the ratio of cis/trans geometry at the proximal position. In mycobacteria such a response was first shown using $M$. phlei by demonstrating that the chain length of the mycolic acids synthesized varied in direct response to growth temperature and that this variation was primarily in the meromycolate portion of the molecule. ${ }^{228,229}$ This adaption has not been reported in slow-growing species of mycobacteria however. In the Nocardia, thermal adaptation occurs by variation in the unsaturation of the meromycolate portion of the mycolic acid chain. ${ }^{35,230}$ In $M$. smegmatis the response occurs through an increased production of the shorter $\alpha^{\prime}$ mycolates and variation in the amount of epoxymycolate formed. ${ }^{231}$ We have shown that in both $M$. smegmatis and the slow-growing pathogen $M$. avium the ratio of cis/trans olefinic mycolate in the proximal position varies directly with growth temperature. ${ }^{222}$ In the case of these mycobacterial species interpretation of the increasing proportion of trans mycolate was complicated by the simultaneous introduction of an allylic methyl branch, which would be expected to have the opposite physical effect. To demonstrate the effect of these substitutions directly cell walls were isolated from organisms grown at different temperatures containing different amounts of trans substituents and it was shown that phase transition temperatures of these walls was directly correlated with the amount of trans substituent. ${ }^{222}$ This property was also shown to be directly correlated with the permeability of the cells grown in this manner when assessed by the uptake of a hydrophobic substance such as chenodeoxycholate or norfloxacin. These results establish that a primary physiological function of the proximal substituent in mycolic acids is the maintenance of a membrane environment of constant fluidity through manipulation of the ratio of cis and trans geometry at this position. 


\section{Trans Cyclopropanation}

Trans cyclopropanes are exceedingly rare in nature and their functions have not been explored in detail. The amount of trans cyclopropane in the proximal position of mycobacterial mycolic acids was shown to have similar effects as trans olefin by isolating purified mycolic acids of defined structural types ( $\alpha$, methoxy, keto) from M. tuberculosis and $M$. avium - organisms which possess very different amounts of trans cyclopropanes in the proximal position. These results established a linear relationship between trans cyclopropylmycolate content and thermal transition temperature in oriented monolayers. These results are in accord with Fluorine-19 NMR studies of membranes of Acholeplasma laidlawii enriched in defined fatty acids in which trans cyclopropane containing membranes were shown to have the highest overall order in a gel state. ${ }^{232}$

We recently reported the isolation of a gene encoding an $S$-adenosyl-L-methionine dependent enzymatic activity which converts a cis olefin to a trans olefin with an allylic methyl branch. ${ }^{121}$ Overexpression of this gene product in $M$. tuberculosis had the effect of drastically increasing the amount of trans substituted mycolic acid at the proximal position in the form of both cyclopropane and olefin. Although this had drastic effects on cell growth and many other physiological characteristics, interpretation of the results obtained were difficult because of a compensatory mechanism in which the amount of methoxy substituent at the distal position was dramatically decreased and the amount of ketone substituent was correspondingly increased. These results highlight the danger of oversimplifying the correlation between the ratio of cis/trans substituent and fluidity; obviously other mycolate substituents as well as perhaps other cellular molecules, can affect fluidity of this membrane system and interpretation may not be straightforward.

\section{Cis Cyclopropanation}

The real biological significance of lipid cis-cyclopropanation remains enigmatic since the observed effects are typically small (this subject has been extensively reviewed recently and will only be briefly touched on here ${ }^{160}$ ). Studies of the physical properties of model lipids from a number of different laboratories have produced varying and inconsistent results indicating either that cyclopropanation enhances or decreases membrane fluidity. In some studies phase transitions of cyclopropane-containing lipids are found to be slightly higher than the corresponding olefinic lipids ${ }^{233,234}$ while in other studies these effects have been modest or even reversed. ${ }^{235}$ Various NMR techniques using either deuterated or fluorinated fatty acids have also demonstrated effects on acyl chain mobility in membrane systems. ${ }^{236-238}$ These studies are consistent with the intuitive picture that the cis cyclopropane functionality serves a fluidizing role (as does its olefinic precursor) but that the extra methylene is either stabilizing to membrane packing or destabilizing depending upon the membrane context in which it occurs. In the mycobacterial system we have seen no effect on phase transition temperatures of isolated cell walls when the distal cis olefin is replaced by a cis cyclopropane but we have observed a $3^{\circ} \mathrm{C}$ increase in the temperature of such transitions when the proximal olefin is replaced. ${ }^{20}$ In this case the proximal cyclopropane lies near the end of the length of the meromycolate branch which is anticipated to interact with the parrallel $\alpha$-branch. Thus this modification may occur in an interface zone between a region of very low permeability and a more fluid lipid zone outside this area. In any case the observed effects on fludity are small and since bacterial mechanisms for regulating membrane fluidity by altering the amount of saturated and unsaturated fatty acids involve much larger relative effects on membrane fluidity it seems unlikely that cis cyclopropanation would be used as an alternative to simply decreasing the amount of unsaturated fatty acid being produced (or proximally trans mycolate).

In E. coli and other bacteria cyclopropanation of plasma membrane constituents happens during the transition from active growth to stationary phase when nutrients are scarce and bulk protein synthesis is declining. ${ }^{239,240}$ This observation suggests that cyclo- 
propanation confers a stabilizing effect on non-growing cells but knockouts of the gene which cyclopropanates lipids in $E$. coli has failed to elucidate a clear phenotypic advantage for non-replicating bacteria. ${ }^{241,242}$

Although cyclopropanation of mycolic acids is observed only in pathogenic mycobacterium such as TB complex, little is known about the physiological function of this modification. In spite of the fact that the physical effects of olefin cyclopropanation are small, the chemical effects are not since cyclopropanes are relatively inert to oxidation. Upon overexpression of the CMAS- 1 protein in M. smegmatis, $25 \%$ of the total mycolates of this organism were cyclopropanated. This modification rendered the fast-growing $M$. smegmatis significantly more resistant to killing by hydrogen peroxide. ${ }^{161}$ E. coli which have been grown on cyclopropane-containing fatty acids, are likewise significantly more resistant to killing by hyperbaric oxygen treatment. ${ }^{243} M$. tuberculosis, in spite of the fact that its intracellular niche is rich in some of the most toxic oxygen species produced, lacks a conventional oxidative stress response system. ${ }^{244}$ Such regulons are typically mediated by a transcription-factor called OxyR which controls the expression of a family of inducible protective proteins. Because of this lack of a defense system to attack by oxidation, M. tuberculosis has been described as constituitively-activated for such systems. As part of this constituitive defense system such adaptations as mycolic acid cyclopropanation, which render the organism more resistant to such killing by toxic oxygen metabolites, may play an important role in the survival and pathogenesis of these organisms.

\section{Oxygenated Mycolates}

Oxygenated mycolates are extremely widespread and only a handful of species appear to be capable of maintaining cell wall function without the presence of such mycolates. In spite of this fact there is very little actual evidence to suggest what physiological role such modifications play in the cell wall. It has been proposed that their function is related to the necessity to provide some hydrophilic attachment points for the association of peripheral cell surface molecules. ${ }^{4}$ Substantiation for this proposal comes from the macroscopic effect of overexpression of the MMAS-4 protein which introduces a secondary alcohol with an adjacent methyl branch into the $\alpha$ myocolates of M. smegmatis. ${ }^{164}$ This substitution results in an extremely hydrophilic surface morphology suggesting that the presence of hydroxy substituents in the distal position of the mycolic acid is capable of allowing an increase in association of hydrophilic components.

Ketomycolate is likely to be very active as a hydrogen-bond acceptor and such a role is consistent with the hydroxymycolate results described above. Methoxymycolate, which has only an ether linkage, is less likely to be very active in this regard. It is noteworthy that the combination of $\alpha$ myocolate with methoxymycolate as the only oxygenated species is not a naturally-occurring combination, whereas the combination of only $\alpha$ and ketomycolate does occur. By manipulating the level of MMAS-3, the enzyme which Omethylates the hydroxymycolate intermediate common to the biosynthesis of both keto and methoxymycolate, ketomycolate can be entirely replaced by methoxymycolate. When this is accomplished in the Pasteur strain of BCG, which normally produces only $\alpha$ and ketomycolate, an isogenic pair of strains with: (1) only $\alpha$ and ketomycolate and, (2) only $\alpha$ and methoxymycolate was created (Yuan, Y., et al., manuscript submitted). Overexpression of this enzyme in $M$. tuberculosis, which normally produces about $20 \%$ ketomycolate, results in the disappearance of ketomycolate and its replacement by methoxymycolate. These strains have allowed us to directly assess the biological significance of ketomycolate production. Many of the characteristics of these two pairs of strains are indistinguishable, including permeation of hydrophobic substances across the cell wall, electron microscopic profiles, and lipid and protein biosynthetic profiles. Permeation of hydrophilic substances, such as glucose, is dramatically affected in these strains which are also significantly more susceptible to antibiotics that inhibit peptidoglycan assembly. The methoxymycolate overproducing strains are also significantly less able 
to tolerate growth temperatures lower than normal and are relatively incapable of growth within macrophages in vitro. These results suggest a subtle but profound perturbation of cell wall function in the absence of the proper wild type amount of ketomycolate. This is consistent with either an effect on porin function or an effect on peptidoglycan assembly and cross-linking.

\section{Physiological Roles of Non-Cell Wall Bound Mycolic Acids}

\section{The Role of Mycolic Acid in the Immune Response to Mycobacterial Infection}

A novel antigen-presenting function has been demonstrated for a non-MHC-encoded molecule that has been designated CD1. ${ }^{245-248} \mathrm{CD} 1$ molecules are a family of non-polymorphic, $\beta 2$-microglobulin-associated glycoproteins that are expressed on most professional antigen-presenting cells. ${ }^{249,250}$ CD1 molecules are recognized by selected $\mathrm{CD}^{-} \mathrm{CD}^{-} \alpha \beta$ or $\gamma \delta \mathrm{TCR}^{+}$T-cell clones ${ }^{251}$ and have been shown to restrict the recognition of foreign microbial antigens by $\alpha \beta \mathrm{TCR}^{+} \mathrm{T}$ cells. ${ }^{250,252,253} \mathrm{CD} 1$ molecules are structurally divergent from MHC class I and class II, ${ }^{247}$ which suggested that the antigens presented by the CD1 system would be drastically different from those presented by MHC-encoded molecules. Recently, mycolic acids of $M$. tuberculosis were reported to be presented by the CD1 system (CD1b) to $\alpha \beta \mathrm{TCR}^{+} \mathrm{T}$ cells, making these lipid antigens active players in the immune recognition of this pathogen. ${ }^{254}$

The crystal structure of mouse CD1d1, which corresponds to human CD1d, has been elucidated $^{255}$ and has revealed that $\mathrm{CD} 1$ adopts a conformation more closely related to that of MHC class I than to that of MHC class II. The binding groove was found to be narrower, but larger because of increased depth, and had only two major pockets that were almost completely hydrophobic. The hydrophobic nature and shape of the CD1 groove was found to be compatible with the earlier observations that human CD1b could present mycolic acids. The putative lipid binding groove of mouse CD1d1 did not have any amphipathic character. It was mostly of neutral charge with no exposed basic groups on its floor that would interact with a buried carboxylate group. It was suggested that CD1-lipid interactions would be different from the binding of fatty acids by fatty acid binding proteins, whereby the lipid is bound through electrostatic interactions between basic residues at the bottom of the binding cavity and the carboxylate group of the fatty acid. ${ }^{256}$ Rather it was proposed that CD1 interacts with lipid in the manner of non-specific lipid transport proteins ${ }^{257}$ whereby the hydrophobic tail is buried in an electrostatically neutral pocket that is lined with hydrophobic residues. ${ }^{255}$

\section{The Role of Mycolic Acids in the Pathogenesis of Mycobacterial Disease}

Mycolic acids, either in the form of cord factor, or other mycolic acid-containing glycolipids (including trehalose mono- and tri-mycolate, glucose mono- and dimycolate) have been heavily implicated in some of the most characteristic pathogenic features of mycobacterial disease.

Cord factor, also known as trehalose dimycolate (TDM) inhibits the migration of blood leukocytes (PMNs). ${ }^{258}$ When injected intraperitoneally into mice in $10 \%$ emulsions of paraffin oil, the animals were killed after repeated injections due to peritonitis and acute hemorrhage. Biochemically these toxic effects were attributed to stimulation of the activity of nicotinamide adenine dinuclease leading to reduced activity of NADdependent microsomal enzymes in various tissues, ${ }^{259}$ depression of muscle and liver glycogen synthesis and pyruvate metabolism, apparently as a direct interaction of cord factor with mitochondrial membranes leading to specific inhibition of oxidative phosphorylation. ${ }^{260}$ Cord factor toxicity seemed to be dependent on the size and distribution of the oil droplets. ${ }^{261}$ Cord factor was not toxic for rats ${ }^{262}$ or for guinea pigs. ${ }^{263}$ Cord factor has also been shown to be involved in granuloma formation. ${ }^{264-271}$ 


\section{Adjuvant Activity and Immunogenicity}

Cord factor also exhibits adjuvant activity. When injected into the foot pads of mice, the mice had an increased antibody response to sheep red blood cells subsequently injected into the same site. ${ }^{272}$ Sheep red blood cells emulsified in incomplete Freund's adjuvant containing $5 \mu \mathrm{g}$ of cord factor induced a very strong antibody response as compared to that after injecting the same amount of antigen in incomplete Freund's adjuvant containing Wax D or mycobacteria. ${ }^{272}$ Adjuvant activity, activation of protein kinase $\mathrm{C}$ resulting in tumour necrosis factor (TNF) release in mouse lung tissues, and lethal toxicity have also been demonstrated for trehalose monomycolate (TMM). ${ }^{273}$

Cord factor has been shown to stimulate non-specific immune resistance against bacterial infections, tumors and parasitic infections. When granulomas were induced in the lungs of mice by intravenous injections of cord factor, local immunity was developed against airborne infections with tubercle bacilli. ${ }^{274,275}$ This immunity was determined to be non-specific resistance because mice pretreated intraperitoneally with cord factor were protected against intraperitoneal challenge with Salmonella typhi or S. typhimurium. ${ }^{276}$ Another example of non-specific antibacterial immunity induced by cord factor was also reported against Klebsiella pneumoniae and Listeria monocytogenes, ${ }^{277}$ and this same group also reported similar results with challenges with these same bacteria with lowmolecular-weight cord factor of $C$. diptheria with corynomycolic acids ranging from $\mathrm{C}_{28}$ to $\mathrm{C}_{36} \cdot{ }^{278}$

Induction of non-specific immunity by cord factor has also been reported against parasites. A single dose of $200 \mu \mathrm{g}$ of TDM in aqueous suspensions protected mice against a challenge with Schistosoma mansoni 10 days later ${ }^{279}$ When a single dose of $300 \mu \mathrm{g}$ of TDM or trehalose dipalmitate was administered subcutaneously before challenge with $S$. mansoni, both compounds gave significant protection, $68 \%$ and $64 \%$, respectively. ${ }^{280}$

Antitumor activity of mycolic acid-containing glycolipids has also been widely documented. Suppressions of urethane induced adenomas and of the growth of Ehrlich ascites tumor cells were achieved after intravenous injection of cord factor into mice. ${ }^{272}$ Incorporation of cord factor in an oil vaccine containing delipidated cell walls of $M$. tuberculosis increased by $83 \%$ the regression in established skin tumors and metastases in draining lymph nodes. ${ }^{281}$ Cord factor in an emulsion of saline and peanut oil had antitumor activity against L1210 leukemia. ${ }^{282}$ Trehalose trimycolate (TTM) was shown to induce tumoricidal activated macrophages. ${ }^{283}$ The immunostimulatory activity of cord factor and similar glycolipids has been postulated to be due to their amphipathic character which allows them to interact strongly with cell membranes, and thus activating immunocytes. ${ }^{284}$ Cord factor has also been reported to have chemotactic properties for peritoneal cells of mice and for peripheral white blood cells of mice and humans, ${ }^{285-287}$ which was suggested as an important factor in antitumor activity via attraction of macrophages.

There is obviously a lot of evidence that mycolic acid-containing glycolipids have the ability to influence pathogenicity, and modulate the immune system. The problem remains though that there is no direct evidence that mycolate-containing molecules are important for virulence since they have been shown to occur in all mycobacterial species, pathogenic as well as non-pathogenic. ${ }^{288}$

\section{REFERENCES}

1. Stodola, F. H., Lesuk, A. and Anderson, R. J., J. Biol. Chem., 1938, 126, 505-513.

2. Anderson, R. J., Chem. Rev., 1941, 29, 225-243.

3. Anderson, R. J., Fortschritte. Chem. Org. Naturst., 1939, 3, 145-202.

4. Minnikin, D. E., in The Biology of the Mycobacteria, Vol. 1, eds C. Ratledge and J. Standford. Academic Press, London, 1982, pp. 95-184.

5. Asselineau, J., Compte Rendu Acad. Sci., 1950, 230, 1620-1622.

6. Asselineau, J. and Lederer, E., Nature, 1950, 166, 782-783. 
7. Luquin, M., Ausina, V., Calahorra, F. L., Belda, F., Barcelo, M. G., Celma, C. and Prats, G., J. Clin. Microbiol., 1991, 29, 120-130.

8. Larsson, L., Jiménez, J., Valero-Guillén, P., Martín-Luengo, F. and Kubín, M., J. Clin. Microbiol., 1989, 27, 2388-2390.

9. Minnikin, D. E. and Polgar, N., Chem. Comm., 1966, 648-649..

10. Etemadi, A. H., Expos. Annu. Biochim. Med., 1967, 28, 77-109.

11. Asselineau, J., Tocanne, G. and Tocanne, J. F., Bull. Chim. Soc. Fr., 1970, 1455-1459.

12. Daffé, M., Lanéelle, M. A. and Valero-Guillen, P. L., Eur. J. Biochem., 1988, 177, 339-344.

13. Lacave, C., Lanéelle, M. A., Daffé, M., Montrozier, H., Rols, M. P. and Asselineau, C., Europ. J. Biochem., 1987, 163, 369-378.

14. Rafidinarivo, E., Prome, J. C. and Levy-Frebault, V., Chem. Phys. Lipids, 1985, 36, 215-228.

15. Daffé, M., Lanéelle, M. A. and Lacave, C., Res. Microbiol., 1991, 142, 397-403.

16. Ioneda, T. and Ishige, M., Chem. Phys. Lipids, 1996, 83, 93-109.

17. Minnikin, D. E., in Bacterial Cell Surface Techniques, eds I. Hancock and I. Poxton. John Wiley and Sons, Chichester, 1988, pp. 125-135.

18. Minnikin, D. E., Hutchinson, I. G., Caldicott, A. B. and Goodfellow, M., J. Chromatog., 1980, 188, 221-233.

19. Valero-Guillén, P. L., Pacheco, F. and Martin-Luengo, F., J. Appl. Bacteriol., 1985, 59, 113-126.

20. George, K. M., Yuan, Y., Sherman, D. R. and Barry, C. E., III., J. Biol. Chem., 1995, 270, $27292-$ 27298.

21. Guerrant, G. O., Lambert, M. A. and Moss, C. W., J. Clin. Microbiol., 1981, 13, 899-907.

22. Kusaka, T. and Mori, T., J. Gen. Microbiol., 1986, 132, 3403-3406.

23. Chun, J., Kang, S. O., Hah, Y. C. and Goodfellow, M., J. Ind. Microbiol., 1996, 17, 205-213.

24. Collins, M. D., Goodfellow, M. and Minnikin, D. E., J. Gen. Microbiol., 1982, 128, 129-149.

25. Goodfellow, M., Weaver, C. R. and Minnikin, D. E., J. Gen. Microbiol., 1982, 128, 731-745.

26. Butler, W. R., Ahearn, D. G. and Kilburn, J. O., J. Clin. Microbiol., 1986, 23, 182-185.

27. Glickman, S. E., Kilburn, J. O., Butler, W. R. and Ramos, L. S., J. Clin. Microbiol., 1994, 32, 740-745.

28. Hamid, M. E., Minnikin, D. E. and Goodfellow, M., J. Gen. Microbiol., 1993, 139, 2203-2213.

29. De Briel, D., Couderc, F., Riegel, P., Jehl, F. and Minck, R., J. Clin. Microbiol., 1992, 30, 1407-1417.

30. Lee, R. E., Armour, J. W., Takayama, K., Brennan, P. J. and Besra, G. S., Biochim. Biophys. Acta, 1997, 1346, 275-284.

31. Rainey, F. A., Klatte, S., Kroppenstedt, R. M. and Stackebrandt, E., Int. J. Syst. Bacteriol., 1995, 45, $32-36$.

32. Koronelli, T. V., Rozynov, B. V., Kvasnikov, E. I., Nogina, T. M. and Nesterenko, O. A., Mikrobiologiia, 1984, 53, 371-373.

33. Baba, T., Nishiuchi, Y. and Yano, I., Int. J. Syst. Bacteriol., 1997, 47, 795-801.

34. Wallace, R. J., Jr., Brown, B. A., Blacklock, Z., Ulrich, R., Jost, K., Brown, J. M., McNeil, M. M., Onyi, G., Steingrube, V. A. and Gibson, J., J. Clin. Microbiol., 1995, 33, 1528-1533.

35. Tomiyasu, I., J. Bacteriol., 1982, 151, 828-837.

36. Beaman, B. L. and Moring, S. E., Infect. Immun., 1988, 56, 557-563.

37. Beaman, B. L., Moring, S. E. and Ioneda, T., J. Bacteriol., 1988, 170, 1137-1142.

38. Koda, S., Fujioka, M. and Shigi, M. et al., J. Gen. Microbiol., 1986, 132, 1547-1551.

39. Ioneda, T. and de Almeida, E. T., Chem. Phys. Lipids, 1991, 59, 225-231.

40. Alshamaony, L., Goodfellow, M., Minnikin, D. E. and Mordarska, H., J. Gen. Microbiol., 1976, 92, 183-187.

41. Bendinger, B., Rainey, F. A., Kroppenstedt, R. M., Moormann, M. and Klatte, S., Int. J. Syst. Bacteriol., 1995, 45, 544-548.

42. Collins, M. D., Simda, J., Dorsch, M. and Stackenbrandt, E., Int. J. Sys. Bacteriol., 1988, 38, 385-391.

43. Tomiyasu, I. and Yano, I., Eur. J. Biochem., 1984, 139, 173-180.

44. Savagnac, A., Aurelle, H., Casas, C., Couderc, F., Gavard, P., Prome, D. and Prome, J. C., Chem. Phys. Lipids, 1989, 51, 31-38.

45. Valero-Guillén, P., Martin-Luengo, F., Jimenez, J. and Larsson, L., Acta Pathol. Microbiol. Immunol. Scand. [B], 1986, 94, 373-376.

46. Minnikin, D. E. and Goodfellow, M., in Microbiological Classification and Identification, eds M. Goodfellow and R. G. Board. Academic Press, London, 1980, pp. 189-256.

47. Minnikin, D. E., Minnikin, S. M., Parlett, J. H., Goodfellow, M. and Magnusson, M., Arch. Microbiol., 1984, 139, 225-231.

48. Minnikin, D. E., Minnikin, S. M., Parlett, J. H. and Goodfellow, M., Zbl. Bakt. Hyg. [A], 1985, 259, 446-460.

49. Minnikin, D. E. and Goodfellow, M., in Twenty-Five Years of Mycobacterial Taxonomy, eds G. P. Kubica, L. G. Wayne and L. S. Good. CDC, US Dept. Health and Human Services, Atlanta, 1980, pp. $159-179$.

50. Butler, W. R. and Kilburn, J. O., J. Clin. Microbiol., 1988, 26, 50-53.

51. Butler, W. R. and Kilburn, J. O., J. Clin. Microbiol., 1990, 28, 2094-2098.

52. Butler, W. R., Jost, K. C., Jr and Kilburn., J. O., J. Clin. Microbiol., 1991, 29, 2468-2472.

53. Floyd, M. M., Silcox, V. A., Jones, W. D., Jr., Butler, W. R. and Kilburn, J. O., J. Clin. Microbiol., 1992, 30, 1327-1330.

54. Duffey, P. S. and Guthertz, L. S., FEMS Microbiol. Lett., 1992, 74, 27-36.

55. Cage, G. D., J. Clin. Microbiol., 1992, 30, 2402-2407.

56. Butler, W. R., Thibert, L. and Kilburn, J. O., J. Clin. Microbiol., 1992, 30, 2698-2704.

57. Thibert, L. and Lapierre, S., J. Clin. Microbiol., 1993, 31, 1759-1763.

58. Guthertz, L. S., Lim, S. D., Jang, Y. and Duffey, P. S., J. Clin. Microbiol., 1993, 31, 1876-1881.

59. Hagen, S. R. and Thompson, J. D., J. Chromatogr. A, 1995, 692, 167-172. 
60. Tortoli, E., Bartoloni, A., Burrini, C., Mantella, A. and Simonetti, M. T., Eur. J. Clin. Microbiol. Infect. Dis., 1995, 14, 240-243.

61. Duffey, P. S., Guthertz, L. S. and Evans, G. C., J. Clin. Microbiol., 1996, 34, 1939-1943.

62. Ritter, D., Carlson, L. D. C., Logan, B. K., Ramos, L. S., Kilburn, J. O. and Coyle, M. B., J. Clin. Microbiol., 1996, 34, 2004-2006.

63. Tortoli, E., Bartoloni, A., Bozzetta, E., Burrini, C., Lacchini, C., Mantella, A., Penati, V., Tullia Simonetti, M. and Ghittino, C., Comp. Immunol. Microbiol. Infect. Dis., 1996, 19, 25-29.

64. Lumb, R., Goodwin, A., Ratcliff, R., Stapledon, R., Holland, A. and Bastian, I., J. Clin. Microbiol., 1997, 35, 2782-2785.

65. Lambert, M. A., Moss, C. W., Silcox, V. A. and Good, R. C., J. Clin. Microbiol., 1986, 23, 731-736.

66. Larsson, L., Jantzen, E. and Johnsson, J., Eur. J. Clin. Microbiol., 1985, 4, 483-487.

67. Kaneda, K., Naito, S., Imaizumi, S., Yano, I., Mizuno, S., Tomiyasu, I., Baba, T., Kusunose, E. and Kusunose, M., J. Clin. Microbiol., 1986, 24, 1060-1070.

68. Kaneda, K., Imaizumi, S. and Yano, I., Microbiol. Immunol., 1995, 39, 563-570.

69. Kaneda, K., Imaizumi, S., Mizuno, S., Baba, T., Tskamura, M. and Yano, I., J. Gen. Microbiol., 1988, 134, 2213-2229.

70. Daffé, M., Lanéelle, M. A., Asselineau, C., Lévy-Frébault, V. and David, H., Ann. Microbiol. (Inst. Pasteur), 1983, 134(B), 241-256.

71. Lévy-Frébault, V., Goh, K. S. and David, H. L., J. Clin. Microbiol., 1986, 24, 835-839.

72. Dobson, G., Minnikin, D. E., Minnikin, S. M., Parlett, J. H., Goodfellow, M., Ridell, M. and Magnusson, M., in Chemical Methods in Bacterial Systematics. (Academic Press, Inc., London, 1985.

73. Minnikin, D. E., Parlett, J. H., Magnusson, M., Ridell, M. and Lind, A., J. Gen. Microbiol., 1984, 130, 2733-2736.

74. Minnikin, D. E., Minnikin, S. M., Dobson, G., Goodfellow, M., Portaels, F., Breen, L. V. D. and Sesardic, D., Journal of General Microbiology, 1983, 129, 889-891.

75. Koukila-Kähkölä, P., Springer, B., Böttger, E. C., Paulin, L., Jantzen, E. and Katila, M. L., Int. J. Syst. Bacteriol., 1995, 45, 549-553.

76. Brander, E., Jantzen, E., Huttunen, R., Julkunen, A. and Katila, M. L., J. Clin. Microbiol., 1992, 30, 1972-1975.

77. Butler, W.R., O’Connor, S.P., Yakrus, M.A., Smithwick, R.W., Plikaytis, B.B., Moss, C.W., Floyd, M.M., Woodley, C.L., Kilburn, J.O., Vadney, F.S., Gross, W.M., Int. J. Syst. Bacteriol., 1993, 43, 539548.

78. Springer, B., Tortoli, E., Richter, I., Grünewald, R., Rüsch-Gerdes, S., Uschmann, K., Suter, F., Collins, M. D., Kroppenstedt, R. M. and Bottger, E. C., J. Clin. Microbiol., 1995, 33, 2805-2811.

79. Minnikin, D. E., Minnikin, S. M. and Goodfellow, M., Biochim. Biophys. Acta, 1982, 712, $616-620$.

80. Ridell, M., Goodfellow, M., Minnikin, D. E., Minnikin, S. M. and Hutchinson, I. G., J. Gen. Microbiol., 1982, 128, 1299-1307.

81. Böttger, E. C., Hirschel, B. and Coyle, M. B., Int. J. Syst. Bacteriol., 1993, 43, 841-843.

82. Coyle, M. B., Carlson, L. C., Wallis, C. K., Leonard, R. B., Raisys, V. A., Kilburn, J. O., Samadpour, M. and Böttger, E. C., J. Clin. Microbiol., 1992, 30, 3206-3212.

83. Portaels, F., Dawson, D. J., Larsson, L. and Rigouts, L., J. Clin. Microbiol., 1993, 31, $26-30$.

84. Haas, W. H., Butler, W. R., Kirschner, P., Plikaytis, B. B., Coyle, M. B., Amthor, B., Steigerwalt, A. G., Brenner, D. J., Salfinger, M., Crawford, J. T., Böttger, E. C. and Bremer, H. J., J. Clin. Microbiol., 1997, 35, 3203-3209.

85. Springer, B., Kirschner, P., Rost-Meyer, G., Schroder, K. H., Kroppenstedt, R. M. and Böttger, E. C., J. Clin. Microbiol., 1993, 31, 3083-3089.

86. Meier, A., Kirschner, P., Schröder, K. H., Wolters, J., Kroppenstedt, R. M. and Böttger, E. C., Int. J. Syst. Bacteriol., 1993, 43, 204-209.

87. Springer, B., Wu, W. K., Bodmer, T., Haase, G., Pfyffer, G. E., Kroppenstedt, R. M., Schröder, K. H., Emler, S., Kilburn, J. O., Kirschner, P., Telenti, A., Coyle, M. B. and Bottger, E. C., J. Clin. Microbiol., 1996, 34, 1100-1107.

88. Datta, A. K., Katoch, V. M., Katoch, K., Sharma, V. D. and Shivannavar, C. T., Int. J. Lepr., 1987, 55, 680-684.

89. Minnikin, D. E., Dobson, G., Goodfellow, M., Draper, P. and Magnusson, M., J. Gen. Microbiol., 1985, 131, 2013-2021.

90. Datta, A. K., Katoch, V. M., Sharma, V. D. and Katoch, K., Int. J. Leprosy, 1985, 53, 45-51.

91. Davidson, L. A., Draper, P. and Minnikin, D. E., J. Gen. Microbiol., 1982, 128, 823-828.

92. Floyd, M. M., Guthertz, L. S., Silcox, V. A., Duffey, P. S., Jang, Y., Desmond, E. P., Crawford, J. T. and Butler, W. R., J. Clin. Microbiol., 1996, 34, 2963-2967.

93. Hinrikson, H. P. and Pfyffer, G. E., Med. Microbiol. Lett., 1994, 3, 49-57.

94. Luquin, M., Lopez, F. and Ausina, V., J. Clin. Microbiol., 1989, 27, 1403-1406.

95. Kazda, J., Stackebrandt, E., Smida, J., Minnikin, D. E., Daffé, M., Parlett, J. H. and Pitulle, C., Int. J. Syst. Bacteriol., 1990, 40, 217-223.

96. Kazda, J., Cooney, R., Monaghan, M., Quinn, P. J., Stackebrandt, E., Dorsch, M., Daffé, M., Müller, K., Cook, B. R. and Tarnok, Z. S., Int. J. Syst. Bacteriol., 1993, 43, 352-357.

97. Lévy-Frébault, V., Rafidinarivo, E. and Prome, J. C. et al., Int. J. Syst. Bacteriol., 1983, 33, $336-343$.

98. Levy-Frebault, V., Daffé, M., Goh, K. S., Lanéelle, M. A., Asselineau, C. and David, H. L., J. Clin. Microbiol., 1983, 17, 744-752.

99. Minnikin, D. E., Minnikin, S. M., Goodfellow, M. and Stanford, J. L., J. Gen. Microbiol., 1982, 128, $817-822$.

100. Luquin, M., Lanéelle, M. A., Ausina, V., Garcia Barcelo, M., Belda, F., Alonso, C. and Prats, G., Int. J. Syst. Bacteriol., 1991, 41, 390-394. 
101. Lacave, C., Lanéelle, M. A., Daffé, M., Montrozier, H., Rols, M. P. and Asselineau, C., Eur. J. Biochem., 1987, 163, 369-378.

102. Minnikin, D. E., Minnikin, S. M., Hutchinson, I. G., Goodfellow, M. and Grange, J. M., J. Gen. Microbiol., 1984, 130, 363-367.

103. Domenech, P., Jimenez, M. S., Menendez, M. C., Bull, T. J., Samper, S., Manrique, A. and Garcia, M. J., Int. J. Syst. Bacteriol., 1997, 47, 535-540.

104. Munoz, M., Julian, E., Garcia-Barcelo, M., Ausina, V. and Luquin, M., J. Chromatogr. B Biomed. Sci. Appl., 1997, 689, 341-347.

105. Wallace, R. J., Jr., Silcox, V. A., Tsukamura, M., Brown, B. A., Kilburn, J. O., Butler, W. R. and Onyi, G., J. Clin. Microbiol., 1993, 31, 3231-3239.

106. Shojaei, H., Goodfellow, M., Magee, J. G., Freeman, R., Gould, F. K. and Brignall, C. G., Int. J. Syst. Bacteriol., 1997, 47, 1205-1207.

107. Luquin, M., Margarit, L., Condom, M. J. and Ausina, V., Int. J. Syst. Bacteriol., 1987, 37, $75-77$.

108. Ausina, V., Luquin, M., Margarit, L. and Prats, G., in Mycobacteria of Clinical Interest, ed. M. Casal. Elsevier Science Publishers B.V., London, 1986, pp. 70-74.

109. Ausina, V., Luquin, M., Garcia Barcelo, M., Lanéelle, M. A., Levy-Frebault, V., Belda, F. and Prats, G., Int. J. Syst. Bacteriol., 1992, 42, 529-535.

110. Luquin, M., Roussel, J., Lopez-Calahorra, F., Lanéelle, G., Ausina, V. and Lanéelle, M. A., Eur. J. Biochem., 1990, 192, 753-759.

111. Luquin, M., Ausina, V., Levy-Frebault, V., Lanéelle, M. A., Belda, F., Barcelo, M. G., Prats, G. and Daffé, M., Int. J. Syst. Bacteriol., 1993, 43, 405-413.

112. Ausina, V., Luquin, M. and Margarit, L., J. Gen. Microbiol., 1985, 131, 2237-2239.

113. Haggblom, M. M., Nohynek, L. J., Palleroni, N. J., Kronqvist, K., Nurmiaho-Lassila, E. L., SalkinojaSalonen, M. S., Klatte, S. and Kroppenstedt, R. M., Int. J. Syst. Bacteriol., 1994, 44, 485-493.

114. Kirschner, P., Teske, A., Schroder, K. H., Kroppenstedt, R. M., Wolters, J. and Bottger, E. C., Int. J. Syst. Bacteriol., 1992, 42, 257-262.

115. Kleespies, M., Kroppenstedt, R. M., Rainey, F. A., Webb, L. E. and Stackebrandt, E., Int. J. Syst. Bacteriol., 1996, 46, 683-687.

116. Kazda, J., Muller, H. J., Stackebrandt, E., Daffé, M., Muller, K. and Pitulle, C., Int. J. Syst. Bacteriol., 1992, 42, 524-528.

117. Valero-Guillen, P. L. and Martin-Luengo, F., FEMS Microbiol Lett, 1986, 35, 59-63.

118. Levy-Frebault, V., Daffé, M., Restrepo, E., Grimont, F., Grimont, P. A. D. and David, H. L., Ann. Inst. Pasteur/Microbiol., 1986, 2, 143-151.

119. Padgitt, P. J. and Moshier, S. E., Int. J. Syst. Bacteriol., 1987, 37, 186-191.

120. Baba, T., Kaneda, K., Kusunose, E., Kusunose, M. and Yano, I., Lipids, 1988, 23, 1132-1138.

121. Yuan, Y., Crane, D. C., Musser, J. M., Sreevatsan, S. and Barry, C. E., III., J. Biol. Chem., 1997, 272, 10041-10049.

122. Wong, M. Y. H. and Gray, G. R., J. Biol. Chem., 1979, 254, 5741-5744.

123. Danielson, S. J. and Gray, G. R., J. Biol. Chem., 1982, 257, 12196-12203.

124. Magnuson, K., Jackowski, S., Rock, C. O. and Cronan, J. E., Jr., Microbiol. Rev., 1993, 57, $522-542$.

125. Wakil, S. J., Stoops, J. K. and Joshi, V. C., Ann. Rev. Biochem., 1983, 52, 537-579.

126. Stoops, J. K., Arslanian, M. J., Oh, Y. H., Aune, K. C., Vanaman, T. C. and Wakil, S. J., Proc. Natl. Acad. Sci. USA, 1975, 72, 1940-1944.

127. Mattick, J. S., Tsukamoto, Y., Nickless, J. and Wakil, S. J., J. Biol.Chem., 1983, 258, 15291-15299.

128. Wong, H., Mattick, J. S. and Wakil, S. J., J. Biol. Chem., 1983, 258, 15305-15311.

129. Jackowski, S., Cronan, J. E., Jr and Rock, C. O., in Biochemistry of Lipids, Lipoproteins and Membranes, eds D. E. Vance and J. Vance. Elsevier Science, 1991, pp. 43-85.

130. Cronan, J. E., Jr and Rock, C. O., in Escherichia coli and Salmonella Cellular and Molecular Biology, ed. Neidhardt. ASM, Washington DC, 1987, pp. 474-497.

131. Cronan, J. E., Jr and Rock, C. O., in Escherichia coli and Salmonella Cellular and Molecular Biology, ed. Neidhardt. ASM Press, Washington DC, 1996, pp. 612-636.

132. Kass, L. R., Brock, D. J. H. and Bloch, K., J. Biol. Chem., 1967, 242, 4418-4431.

133. Bergler, H., Wallner, P., Ebeling, A., Leitinger, B., Fuchsbichler, S., Aschauer, H., Kollenz, G., Hogenauer, G. and Turnowsky, F., J. Biol. Chem., 1994, 269, 5493-5496.

134. Bloch, K., Meth. Enzymol., 1975, 35, 84-90.

135. Brindley, D., Matsumura, S. and Bloch, K., Nature, 1969, 224, 666-669.

136. Bloch, K., Adv. Enzymol. Relat. Areas Mol. Biol., 1977, 45, 1-84.

137. Kikuchi, S., Rainwater, D. L. and Kolattukudy, P. E., Arch. Biochem. Biophys., 1992, 295, 318-326.

138. Fernandes, N. D. and Kolattukudy, P. E., Gene, 1996, 170, 95-99.

139. Kiho, T. and Ballou, C. E., Biochemistry, 1988, 27, 5824-5828.

140. Maggio, J. E., Proc. Natl. Acad. Sci. USA, 1980, 77, 2582-2586.

141. Qureshi, N., Sathyamoorthy, N. and Takayama, K., J. Bacteriol., 1984, 157, 46-52.

142. Takayama, K., Wang, L. and David, H. L., Antimicrob. Agents Chemother., 1972, 2, $29-35$.

143. Takayama, K., Schnoes, H. K., Armstrong, E. L. and Boyle, R. W., J. Lipid Res., 1975, 16, $308-317$.

144. Mdluli, K., Slayden, R. A., Zhu, Y., Ramaswamy, S., Pan, X., Mead, D., Crane, D. D., Musser, J. M. and Barry, C. E. III (1998) Science 1988, 280, 1607-1610.

145. Hopwood, D. A., Chem. Rev., 1997, 97, 2465-2497.

146. Banerjee, A., Dubnau, E., Quemard, A., Balasubramanian, V., Um, K.S., Wilson, T., Collins, D., Lisle, G.d. and Jacobs, W.R., Jr, Science, 1994, 263, 227-230.

147. Dessen, A., Quenmard, A., Blanchard, J. S., Jacobs, W. R., Jr and Sacchettini., J. C., Science, 1995, 267, 1638-1641.

148. Quemard, A., Sacchettini, J. C., Dessen, A., Vilcheze, C., Bittman, R., Jacobs, W. R., Jr and Blanchard., J. S., Biochemistry, 1995, 34, 8235-8241. 
149. Sacchettini, J. C. and Blanchard, J. S., Res. Microbiol., 1996, 147, 36-43.

150. Mdluli, K., Sherman, D. R., Hickey, M. J., Kreiswirth, B. N., Morris, S., Stover, C.K. and Barry, C. E., III., J. Inf. Dis., 1996, 174, 1085-1090.

151. Qureshi, N., Takayama, K. and Schnoes, H. K., J. Biol. Chem., 1980, 255, 182-189.

152. Takayama, K., Qureshi, N. and Schnoes, H. K., Lipids, 1978, 13, 575-579.

153. Sathyamoorthy, N., Qureshi, N. and Takayama, K., Can. J. Microbiol., 1985, 31, 214-219.

154. Couderc, F., Lipids, 1995, 30, 691-699.

155. Jackson, M., Portnoi, D., Catheline, D., Dumail, L., Rauzier, J., Legrand, P. and Gicquel, B., Infect Immun., 1997, 65, 2883-2889.

156. Gastambide-Odier, M., Delaumeny, J. M. and Lederer, E., Compte rendu Hebd. Acad. Sci., 1964, 259, 3404-3407.

157. Etemadi, A. H. and Lederer, E., Biochim. Biophys. Acta, 1965, 98, 160-167.

158. Wong, M. Y. H., Steck, P. A. and Gray, G. R., J. Biol. Chem., 1979, 254, 5734-5740.

159. Lederer, E., Q. Rev. Chem. Soc., 1969, 23, 453-481.

160. Grogan, D. W. and Cronan, J. E., Jr., Microbiol. Mol. Biol. Rev., 1997, 61, 429-441.

161. Yuan, Y., Lee, R. E., Besra, G. S., Belisle, J. T. and Barry, C. E., III., Proc. Natl. Acad. Sci. USA, 1995 , 92, 6630-6634.

162. Wang, A.-Y., Grogan, D. W. and Cronan, J. E., Jr., Biochemistry, 1992, 31, 11020-11028.

163. Minnikin, D. E. and Polgar, N., Chem. Comm., 1967, 1064, 1172-1174.

164. Yuan, Y. and Barry, C. E., III., Proc. Natl. Acad. Sci. USA, 1996, 93, 12828-12833.

165. Quemard, A., Lanéelle, M. A., Marrakchi, H., Prome, D., Dubnau, E. and Daffé, M., Eur. J. Biochem., 1997, 250, 758-763.

166. Minnikin, D. E. and Polgar, N., Chem. Comm., 1967, 785, 916-918.

167. Dubnau, E., Lanéelle, M. A., Soares, S., Benichou, A., Vaz, T., Prome, D., Prome, J. C., Daffé, M. and Quemard, A., Mol. Microbiol., 1997, 23, 313-322.

168. Dougherty, D. A., Science, 1996, 271, 163-168.

169. Etemadi, A. H. and Gasche, J., Bull. Soc. Chim. Biol. (Paris), 1965, 47, 2095-2104.

170. Toriyama, S., Imaizumi, S., Tomiyasu, I., Masui, M. and Yano, I., Biochim. Biophys. Acta, 1982, 712, 427-429.

171. Reiser, S. and Somerville, C., J. Bacteriol., 1997, 179, 2969-2975.

172. Wang, L., Takayama, K., Goldman, D. S. and Schnoes, H. K., Biochim. Biophys. Acta, 1972, 260, 4148.

173. Takayama, K. and Davidson, L. A., Trends Biochem. Sci., 1979, 14, 280-282.

174. Takayama, K. and Qureshi, N., in The Mycobacteria: A Sourcebook, Part A, Vol. 15, eds G. P. Kubica and L. G. Wayne. Marcel Dekker, New York, 1984, pp. 315-344.

175. Gastambide-Odier, M. and Lederer, E., Nature, 1959, 184, 1563-1564.

176. Gastambide-Odier, M. and Lederer, E., Biochem. Z., 1960, 333, 285-295.

177. Chevalier, J., Pommier, M. T., Cremieux, A. and Michel, G., J. Gen. Microbiol., 1988, 134, $2457-2461$.

178. Couderc, F., De Briel, D., Demont, N., Gilard, V. and Prome, J. C., J. Gen. Microbiol., 1991, 137, 19031909.

179. Etemadi, A. H., Bull. Soc. Chim. Biol., 1967, 49, 695-706.

180. Walker, R. W., Prome, J. and Lacave, C. S., Biochim. Biophys. Acta, 1973, 326, 52-62.

181. Prome, J. C., Walker, R. W. and Lacave, C., C.R. Acad. Sci. Paris, Ser. G., 1974, 278, $1065-1068$.

182. Ahibo-Coffy, A., Aurelle, H. and Lacave, C., Chem. Phys. Lipids, 1978, 22, 185-195.

183. Shimakata, T., Iwaki, M. and Kusaka, T., Arch. Biochem. Biophys., 1984, 229, 329-339.

184. Shimakata, T., Iwaki, M. and Kusaka, T., Arch. Biochem. Biophys., 1985, 238, 497-508.

185. Puzo, G., Tissie, G., Aurelle, H., Lacave, C. and Prome, J. C., Eur. J. Biochem., 1979, 98, 99-105.

186. Datta, A. K. and Takayama, K., Biochim. Biophys. Acta, 1993, 1169, 135-145.

187. Besra, G. S., Sievert, T., Lee, R. E., Slayden, R. A., Brennan, P. J. and Takayama, K., Proc. Natl. Acad. Sci. USA, 1994, 91, 12735-12739.

188. Belisle, J. T., Vissa, V. D., Sievert, T., Takayama, K., Brennan, P. J. and Besra, G. S., Science, 1997 , 276, 1420-1422.

189. Walsh, C., Enzymatic Reaction Mechanisms. W. H. Freeman and Company, New York, 1979.

190. Lacave, C., Quemard, A. and Lanéelle, G., Biochim. Biophys. Acta, 1990, 1045, 58-68.

191. Lacave, C., Lanéelle, M. A. and Lanéelle, G., Biochim. Biophys. Acta, 1990, 1042, 315-323.

192. Lopez-Marin, L. M., Quemard, A., Lanéelle, G. and Lacave, C., Biochim. Biophys. Acta, 1991, 1086, $22-$ 28.

193. Wheeler, P. R., Besra, G. S., Minnikin, D. E. and Ratledge, C., Biochim. Biophys. Acta, 1993, 1167, 182 188 .

194. Besra, G. S., Minnikin, D. E., Wheeler, P. R. and Ratledge, C., Chem. Phys. Lipids, 1993, 66, $23-34$.

195. Rastogi, N., Res. Microbiol., 1991, 142, 464-476.

196. Nikaido, H., Science, 1994, 264, 382-388.

197. Barry, C. E., III and Mdluli., K., Trends Microbiol., 1996, 4, 275-281.

198. Clemens, D. L., Trends Microbiol., 1997, 5, 383-385.

199. Armstrong, J. A. and D'Arcy Hart, P., J. Exp. Med., 1971, 134, 713-740.

200. Jarlier, V. and Nikaido, H., J. Bacteriol., 1990, 172, 1418-1423.

201. Trias, J. and Benz, E., Mol. Microbiol., 1994, 14, 283-290.

202. Chambers, H. F., Moreau, D., Yajko, D., Miick, C., Wagner, C., Hackbarth, C., Kocagoz, S., Rosenberg, E., Hadley, W. K. and Nikaido, H., Antimicrob. Agents Chemother., 1995, 39, 2620-2624.

203. Liu, J., Barry, C. E. III and Nikaido, H., in Mycobacteria: Molecular Biology and Virulence, eds C. Ratledge and J. W. Dale. Chapman and Hall, 1998, pp. 1-44.

204. Jarlier, V. and Nikaido, H., FEMS Microbiol. Lett., 1994, 123, 11-18. 
205. Bendinger, B., Rijnaarts, H. H. M., Altendorf, K. and Zehnder, A. J. B., Appl. Environ. Microbiol., 1993, 59, 3973-3977.

206. Barksdale, L. and Kim, K.-S., Bacteriol. Rev., 1977, 41, 217-372.

207. Goren, M. B., Cernich, M. and Brokl, O., Am. Rev. Respir. Dis., 1978, 118, 151-154.

208. Trias, J., Jarlier, V. and Benz, R., Science, 1992, 258, 1479-1481.

209. Trias, J. and Benz, R., J. Biol. Chem., 1993, 268, 6234-6240.

210. Duchene, M., Schweizer, A., Lottspeich, F., Krauss, G., Marget, M., Vogel, K., von Sprecht, B. U. and Domdey, H., J. Bacteriol., 1988, 170, 155-162.

211. Daffé, M. and Draper, P., Adv. Microb. Physiol., 1998, 39, 131-203.

212. Brennan, P. J. and Nikaido, H., Annu. Rev. Biochem., 1995, 64, 29-63.

213. Imaeda, T., Kanetsuna, F. and Galindo, B., J. Ultrastructural Res., 1968, 25, 46-63.

214. Mdluli, K., Swanson, J., Fischer, E., Lee, R. E. and Barry, C. E. III. Mol. Microbiol. 1998, $27,1223-1233$.

215. Paul, T. R. and Beveridge, T. J., J. Bacteriol., 1992, 174, 6508-6517.

216. Paul, T. R. and Beveridge, T. J., Zbl. Bakt., 1993, 279, 450-457.

217. Paul, T. R. and Beveridge, T. J., Infect. Immun., 1994, 62, 1542-1550.

218. Lee, R. E., Brennan, P. J. and Besra, G. S., Curr. Top. Microbiol. Immunol., 1996, $215,1-27$.

219. Goren, M. B., in The Mycobacteria: A Sourcebook, Part A., eds G. P. Kubica and L. G. Wayne. Marcell Dekker, Inc., New York and Basel, 1984, pp. 379-415.

220. Nikaido, H., Kim, S.-H. and Rosenberg, E. Y., Mol. Microbiol., 1993, 8, 1025-1030.

221. Liu, J., Rosenberg, E. Y. and Nikaido, H., Proc. Natl. Acad. Sci. USA, 1995, 92, 11254-11258.

222. Liu, J., Barry, C. E., III., Besra, G. S. and Nikaido, H., J. Biol. Chem., 1996, 271, 29545-29551.

223. Singer, S. J. and Nicolson, G. L., Science, 1972, 175, 720-731.

224. Wilson, M. A. and Pohorille, A., J. Am. Chem. Soc., 1996, 118, 6580-6587.

225. Durand, E., Welby, M., Laneele, G. and Tocanne, J.-F., Eur. J. Biochem., 1979, 93, $103-112$.

226. Durand, E., Gillois, M., Tocanni, J.-F. and Laneele, G., Eur. J. Biochem., 1979, 94, 109-118.

227. Sinensky, M., Proc. Nat. Acad. Sci. USA, 1974, 71, 522-525.

228. Toriyama, S., Yano, I., Masui, M., Kusunose, M. and Kusunose, E., FEBS Lett., 1978, 95, 111-115.

229. Toriyama, S., Yano, I., Masui, M., Kusunose, E., Kusunose, M. and Akimori, N., J. Biochem., 1980, 88, 211-221.

230. Tomiyasu, I., Toriyama, S., Yano, I. and Masui, M., Chem. Phys. Lipids, 1981, 28, 41-54.

231. Baba, T., Kaneda, K., Jusunose, E., Kusunose, M. and Yano, I., J. Biochem., 1989, 106, 81-86.

232. Macdonald, P. M., Sykes, B. D. and McElhaney, R. N., Biochemistry, 1985, 24, 4651-4659.

233. Silvius, J. R. and McElhaney, R. N., Chem. Phys. Lipids, 1979, 25, 125-134.

234. McGarrity, J. T. and Armstrong, J. B., Biochim. Biophys. Acta, 1981, 640, 544-548.

235. Perly, B., Smith, I. C. P. and Jarrell, H. C., Biochemistry, 1985, 24, 1055-1063.

236. Dufourc, E. J., Smith, I. C. P. and Jarrell, H. C., Chem. Phys. Lipids, 1983, 33, 153-177.

237. Dufourc, E. J., Smith, I. C. P. and Jarrell, H. C., Biochemistry, 1984, 23, 2300-2309.

238. Jarrell, H. C., Tulloch, A. and Smith, I. C. P., Biochemistry, 1983, 22, 5611-5619.

239. Wang, A.-Y. and Cronan, J. E., Jr., Mol. Microbiol., 1994, 11, 1009-1017.

240. Guckert, J. B., Hood, M. A. and White, D. C., Appl. Environ. Microbiol., 1986, 52, 794-801.

241. Grogan, D. W. and Cronan, J. E., Jr., J. Bacteriol., 1984, 158, 286-295.

242. Grogan, D. W. and Cronan, J. E., Jr., J. Bacteriol., 1986, 166, 872-877.

243. Harley, J. B., Santangelo, G. M., Rasmussen, H. and Goldfine, H., J. Bacteriol., 1978, 134, 808-820

244. Sherman, D. R., Sabo, P. J., Hickey, M. J., Arain, T. M., Mahairas, G. G., Yuan, Y., Barry, C. E., III and Stover., C. K., Proc. Natl. Acad. Sci. USA, 1995, 92, 6625-6629.

245. Calabi, F. and Milstein, C., Nature, 1986, 323, 540-543.

246. Terhorst, C., Agthoven, K. L., Snow, P., Reinherz, E. and Schlossman, S., Cell, 1981, 23, 771-780.

247. Calabi, F., Jarvis, J. M., Martin, L. and Milstein, C., Eur. J. Immun., 1989, 19, $285-292$.

248. Balk, S. P., Bleicher, P. A. and Terhorst, C., Proc. Natl. Acad. Sci. USA, 1989, 86, 252-256.

249. Porcelli, S., Brenner, M. B. and Band, H., Immun. Rev., 1991, 120, 137-183.

250. Porcelli, S., Morita, C. T. and Brenner, M. B., Nature, 1992, 360, 593-597.

251. Porcelli, S., Brenner, M. B., Greenstein, J. L., Balk, S. P., Terhorst, C. and Bleicher, P. A., Nature, 1989 , 341, 447-450.

252. Faure, F., Jitsukawa, S., Miossec, C. and Hercend, T., Eur. J. Immun., 1990, 20, 703-706.

253. Balk, S. P., Ebert, E. C., Blumenthal, R. L., McDermott, F. V., Wucherpfennig, K. W., Landau, S. B. and Blumberg, R. S., Science, 1991, 253, 1411-1415.

254. Beckman, E. M., Porcelli, S. A., Morita, C. T., Behar, S. M., Furlong, S. T. and Brenner, M. B., Nature, 1994, 372, 691-694.

255. Zeng, Z. H., Castano, A. R., Segelke, B. W., Stura, P. A., Peterson, E. A. and Wilson, I. A., Science, 1997, 277, 339-345.

256. Lalonde, J. M., Levenson, M. A., Roe, J. J., Bernlohr, D. A. and Banaszak, L. J., J. Biol. Chem., 1994, 269, 25339-25347.

257. Shin, D. H., Lee, J. Y., Hwang, K. Y., Kim, K. K. and Suh, S. W., Structure, 1995, 3, 189-199.

258. Bloch, H., J. Exp. Med., 1950, 91, 197-217.

259. Artman, M., Bekierkunst, A. and Goldberg, I., Arch. Biochem. Biophys., 1964, 105, 80-85.

260. Kato, M., Arch. Biochem. Biophys., 1970, 140, 379-390.

261. Yarkoni, E. and Rapp, H. J., Infect. Immun., 1977, 18, 552-554.

262. Saito, R., Tanaka, A., Sugiyama, K. and Kato, M., Am. Rev. Resp. Dis., 1975, 112, 578-580.

263. Adam, A., Ciorbaru, R., Petit, J. F. and Lederer, E., Proc. Natl. Acad. Sci. USA, 1972, 69, 851-854.

264. Bekierkunst, A., Int. J. Cancer, 1975, 16, 442-447.

265. McLaughlin, C. A., Parker, R., Hadlow, W. J., Toubiana, R. and Ribi, E. E., Cell. Immunol., 1978, 38, 14-24.

266. Meyer, J. T., Ribi, E. E. and Azuma, I., Cell. Immunol., 1975, 16, 11-24. 
267. Rastogi, N. and David, H. L., Biochimie, 1988, 70, 1101-1120.

268. Han, Y., He, H., Oka, S. and Yano, I., Acta Lepr., 1989, 7, 130-132.

269. Kaneda, K., Sumi, Y., Kurano, F., Kato, Y. and Yano, I., Infect. Immun., 1986, 54, 869-875.

270. Matsunaga, I., Oka, S., Fujiwara, N. and Yano, I., J. Biochem., 1996, 120, 663-670.

271. Gotoh, K., Mitsuyama, M., Imaizumi, S., Kawamura, I. and Yano, I., Microbiol. Immunol., 1991, 35, $175-185$.

272. Bekierkunst, A., Levij, I. S., Yarkoni, E., Vilkas, E. and Lederer, E., Science, 1971, 174, $1240-1242$.

273. Numata, F., Ishida, H., Nishimura, K., Sekikawa, I. and Azuma, I., J. Carb. Chem., 1986, 5, $127-138$.

274. Bekierkunst, A., J. Bacteriol., 1968, 96, 958-961.

275. Ribi, E. E., Milner, K. C., Granger, D. L., Kelly, M. T., Yamamoto, K., Brehmer, W., Parker, R., Smith, R. F. and Strain, S. M., Ann. NY Acad. Sci., 1976, 277, 228-235.

276. Yarkoni, E. and Bekierkunst, A., Infect. Immun., 1976, 14, 1125-1129.

277. Parant, M., Prant, F., Chedid, L., Draier, J. C., Petit, J. F., Wietzerbin, J. and Lederer, E., J. Infect. Dis., 1977, 135, 771-777.

278. Parant, M., Audibert, F., Parant, F., Chedid, L., Soler, E., Polonsky, J. and Lederer, E., Infect. Immun., 1978, 20, 12-19.

279. Mahmoud, A. A. F., Civil, R. H. D., Lederer, E. and Chedid, L., Clin. Res., 1977, 25, 380A-385A.

280. Olds, G. R., Chedid, L., Lederer, E. and Mahmoud, A. F., J. Inf. Dis., 1980, 141, 473-478.

281. Bekierkunst, A., Wang, L., Toubiana, R. and Lederer, E., Infect. Immun., 1974, 10, 1044-1050.

282. Leclerc, C., Lamensans, A., Chedid, L., Drapier, J. C., Petit, J. F., Wietzerbin, J. and Lederer, E., Cancer Immunol. Immunother., 1976, 1, 227-232.

283. Furukawa, M., Ohtsubo, Y., Sugimoto, N., Katoh, Y. and Dohi, Y., FEMS Microbiol. Immunol., 1990, 64, 83-88.

284. Kato, M., Am. Rev. Respir. Dis., 1969, 100, 47-53.

285. Ofek, I. and Bekierkunst, A., J. Natl. Cancer Inst., 1976, 57, 1379-1381.

286. Yarkoni, E., Wang, L. and Bekierkunst, A., Infect. Immun., 1977, 16, 1-8.

287. Matsunaga, I., Oka, S., Inoue, T. and Yano, I., FEMS Microbiol. Lett., 1990, 67, 49-54.

288. Goren, M. B. and Brennan, P. J., in Tuberculosis, ed. G. P. Youmans. W.B. Saunders Co., Philadelphia, 1979, pp. 63-193. 